\title{
Variabilidade do sistema praia-dunas frontais para o litoral norte do Rio Grande do Sul (Palmares do Sul a Torres, Brasil) com o auxílio do Light De- tection and Ranging - Lidar
}

\author{
Humberto Dias VIANNA ${ }^{1}$ \& Lauro Julio CALLIARI ${ }^{2}$
}

1 Laboratório de Oceanografia Geológica, Universidade Federal do Rio Grande. Av. Itália, km 8, Rio Grande, CEP 96203-900, RS, Brasil. E-mail: hvianna@furg.br.

2 Programa de Pós-graduação Oceanografia Física Química e Geológica, Universidade Federal do Rio Grande. Av. Itália, km 8, Rio Grande, CEP 96203-900, RS, Brasil. E-mail: lcalliari@log.furg.br.

Recebido em 05/2014. Aceito para publicação em 06/2015.

Versão online publicada em 19/08/2015 (www.pesquisasemgeociencias.ufrgs.br)

\begin{abstract}
Resumo - Parâmetros morfométricos e geológicos, como orientação da linha de costa, potencial de deriva de vento, declividade e largura da praia subaérea, percentual de areia média e tamanho médio do grão, são determinantes para a geomorfologia do sistema praia-duna frontal. Levantamentos feitos no litoral norte do Rio Grande do Sul (RS) através do sistema laser scanner permitiram a obtenção contínua dos principais parâmetros morfométricos, de forma rápida e precisa, sem a necessidade de levantamentos em campo. A variabilidade lateral desses parâmetros e sua associação com as características geológicas foram consideradas para um setor de praia de $123 \mathrm{~km}$ entre Palmares do Sul e Torres através de análises cluster e escalonamento multidimensional, as quais definiram quatro grupos de afinidade. As variáveis que mais contribuíram para a diferenciação dos grupos foram: largura da praia subaérea, potencial de deriva de vento, azimute da linha de costa e percentual de areia média. Os grupos 1 e 4, situados mais ao sul da área de estudo, possuem balneários com maior largura da praia subaérea, potencial de deriva de vento e variação de volume acima do datum, e apresentam os menores azimutes da linha de costa. 0 grupo 1 mostra o maior volume de perfil e altura das dunas frontais. 0 menor volume de perfil pertence ao grupo 3, consequência do maior azimute da linha de costa, responsável pela entrada quase paralela do vento dominante no sistema praia-duna e menor potencial de deriva de vento. 0 grupo 2 é caracterizado por valores de largura da praia subaérea semelhante ao grupo 3, porém possui maior volume de perfil e altura das dunas frontais. Essas diferenças podem ser explicadas pelo menor azimute da linha de costa do grupo 2. As variáveis largura da praia subaérea, potencial de deriva de vento e azimute da linha de costa e as características granulométricas da praia são fundamentais para explicar a variabilidade das dunas frontais no litoral norte do RS.
\end{abstract}

Palavras chave: Relações duna-praia, light detection and ranging, morfometria de dunas.

Abstract - VARIABILITY OF THE BEACH-DUNES SYSTEM FOR THE NORTH COAST OF RIO GRANDE DO SUL
(PALMARES DO SUL TO TORRES, BRAZIL) SUPPORTED BY LIGHT DETECTION AND RANGING - LIDAR. Mor-
phometric and geological parameters such as coastline orientation, wind drif potential, subaerial
beach slope and width and mean grain size are crucial to the geomorphology of the beach-dune
system. Surveys on the northern coast of the Rio Grande do Sul (RS) through the laser scanner sys-
tem provided major morphometric parameters quickly and accurately without the need for in situ
surveys. The lateral variability of these parameters and their association with geological features
were analyzed through cluster analysis and multidimensional scaling for the beach sectors along
123 km between the balnearies of Palmares do Sul and Torres defining four affinity groups. The
variables that contributed most to the differentiation of the groups were: width of the subaerial
beach, wind drift potential, coastline azimuth and percentage of medium sand. Groups 1 and 4, lo-
cated further south of the study area, have beaches with wider sub aerial beach profiles, wind drift
potential, volume change above the datum, and have the lowest azimuths of the shoreline. Group 1
displays the highest volume and height of the foredunes. The lower volume of the foredunes are as-
sociated to group 3, which displays the higher azimuth of the shoreline implying in a almost parallel
wind to the coastline which reflect in a low wind drift potential. Group 2 shows values of subaerial
beach width similar to group 3, but displays a greater foredune volume and height being these
differences explained by its lower coastline azimuth. The variables width of the subaerial beach,
wind drift potential and coastline azimuth associated with the beach mean grain size are important
factors to explain the variability of the foredunes along the northern coast of the RS.
Keywords: Interrelation dune beach, Lidar, dune morphometry. 


\section{Introdução}

O tamanho absoluto das dunas frontais e dos sistemas dunares transgressivos é influenciado por três fatores primários: velocidade dos ventos incidentes, tamanho médio do grão e orientação da linha de costa em relação ao vento dominante (Bagnold, 1941). Um fator importante que favorece a formação de dunas com grande volume é a alta energia de ondas com período longo, uma vez que promove condições para a transferência de sedimentos da antepraia (shoreface) para a zona de arrebentação e daí para a praia (Short \& Hesp, 1982).

Considerando que numa área exista incidência de ventos em direção ao continente, as praias dissipativas apresentam maior altura das dunas frontais, visto que são constituídas de areia fina, perfil de baixa declividade e maior largura propiciando mínimo distúrbio no fluxo do vento. Adicionalmente, devido à alta energia de ondas, apresentam acentuado spray salino, o que favorece a existência de uma vegetação com baixa diversidade e zonação pronunciada. Todos estes fatores associados à baixa mobilidade da praia condicionam um potencial elevado na formação de dunas frontais altas (Short \& Hesp, 1982). Praias intermediárias são caracterizadas por energia moderada de ondas, granulometria média, zona de surf comple$\mathrm{xa}$, geralmente caracterizada por ritmicidades topográficas tanto na porção subaérea como na subaquosa. Distúrbios no fluxo do vento aumentam com a elevação do gradiente da praia, diminuindo o potencial de transporte eólico e, consequentemente, reduzindo a altura das dunas frontais. Praias intermediárias de alta energia podem apresentar campos de dunas transgressivos sem vegetação, rupturas de deflação (blowouts) e dunas parabólicas de menor proporção, quando comparados às praias dissipativas (Short \& Hesp, 1982). Poucos e discretos blowouts e dunas parabólicas são encontrados em praias intermediárias de moderada a baixa energia.

As relações entre as características morfométricas e a altura das dunas frontais podem ser modificadas por uma série de fatores naturais e antrópicos. Em certos trechos do litoral norte e médio do Rio Grande do Sul (RS), observa-se aumento progressivo na altura das dunas frontais de Torres a Palmares do Sul e, provavelmente nesse trecho, as relações morfométricas entre praia e duna frontal seguem os aspectos apontados na literatura, uma vez que a orientação da costa em relação ao vento predominante favorece o transporte eólico em direção ao continente. Possivelmente ali, as relações entre a morfometria das praias, altura e estabilidade das dunas frontais encaixam-se nos padrões já descritos na literatura.

Levantamentos recentes realizados com um equipamento de varredura Light Detection And Ranging (Lidar), ao longo do setor entre Palmares do Sul e Torres, forneceram uma base de dados onde é possível obter infinitos perfis transversais ao sistema praia-duna, nos quais parâmetros físicos podem ser levantados como, por exemplo, altura das dunas, largura e declividade da praia, assim como a geomorfologia detalhada da área levantada. Esses dados, associados aos processos responsáveis pela morfodinâmica atual, proporcionam uma boa oportunidade para se verificar, em maior detalhe, a existência da variabilidade lateral e seus padrões característicos.

Estima-se que, com a precisão fornecida pelo Lidar ao longo de uma faixa de praia com $130 \mathrm{~km}$, seja possível explicar a variabilidade lateral na altura das dunas e demais variações morfométricas ao longo do trecho estudado. Este trabalho tem como objetivo identificar, através dos dados planialtimétricos do Lidar e dos parâmetros morfométricos, os principais fatores responsáveis pela variabilidade lateral do sistema praia-dunas frontais entre Palmares do Sul a Torres no litoral norte do RS.

\section{2 Área, materiais e métodos}

O litoral norte gaúcho é formado pelos municípios de Palmares do Sul, Balneário Pinhal, Cidreira, Tramandaí, Imbé, Osório, Xangri-lá, Capão da Canoa, Terra de Areia, Arroio do Sal e Torres, sendo limitado ao sul pelo farol Berta e ao norte pelo rio Mampituba (Fig. 1). Esses municípios possuem uma linha de costa suavemente curva, com 126,5 km de extensão, de orientação sudoeste-nordeste. A linha de costa é interrompida por duas desembocaduras, ao sul pelo Rio Tramandaí (divisa entre os municípios de Tramandaí e Imbé) e ao norte pelo Rio Mampituba (divisa entre os estados do Rio Grande do Sul e Santa Catarina), ambas fixadas por estruturas oceânicas do tipo molhes.

\subsection{Clima}

A região de estudo está localizada na zona de influência do clima subtropical I, subclassificação Ib, caracterizado por ser pouco úmido com inverno frio e verão quente (Rossato, 2011) e influência dos sistemas polares com maior participação de sistemas tropicais continentais em associação com o efeito da continentalidade e do relevo. Os sistemas frontais são responsáveis pela maior parte 


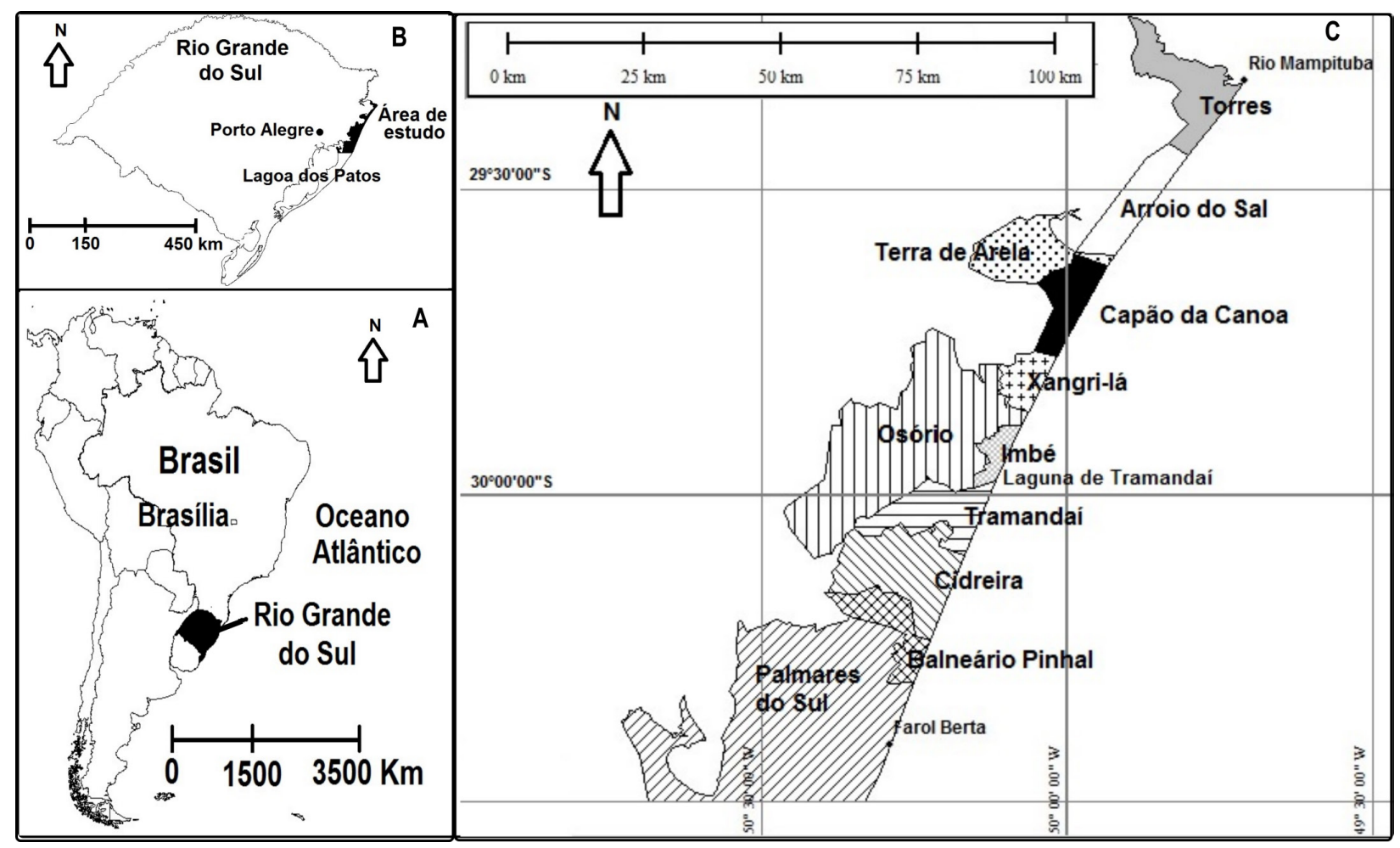

Figura 1. Área de estudo no território brasileiro (A), no estado do Rio Grande do Sul (B), e os municípios constituintes da área de estudo (C).

das precipitações. Chove entre $1400-1700 \mathrm{~mm} /$ ano, de forma concentrada em 70-90 dias de chuva. A precipitação ocorre entre 6-9 dias/mês, principalmente nos equinócios. A temperatura média anual é amena, varia de 20 a $23^{\circ} \mathrm{C}$ : no mês mais frio oscila entre 11 e $14^{\circ} \mathrm{C}$ e no mês mais quente, entre 23- $29^{\circ}$ (Rossato, 2011).

Tomazelli (1993) efetuou a análise de séries temporais de vento, entre 1970 e 1982, obtidas das estações meteorológicas de Torres, Imbé e Rio Grande, determinando a direção e velocidade dominante. 0 estudo mostrou que o vento nordeste (NE) é o mais frequente, seguido pelos ventos Sul (S), em Torres, e Oeste (0), em Imbé. A frequência do vento NE, durante o ano, alcança valores entre 24,1 \% (Torres) e 41,4 \% (Imbé). A maior frequência percentual de NE ocorre em dezembro com 53,2 \% (Imbé) e novembro com 62,7 \% (Torres).

\subsection{Geologia, geomorfologia e hidrografia}

A área de estudo situa-se na barreira holocênica IV (Tomazelli \& Villwock, 2000) a qual apresenta características progradantes entre Torres e Tramandaí e agradacionais (estacionárias) em Dunas Altas (Dillenburg \& Hesp, 2009; Dillenburg et al., 2013). Já em Jardim do Éden e Cidreira, a barreira apresenta características retrogradacionais (Travessas et al., 2005).
Os balneários que constituem os citados municípios, segundo Calliari et al. (2006), são formados por praias de características intermediárias a dissipativas com índice de mobilidade moderado a alto. Essa afirmação não se aplica às praias protegidas por promontórios em Torres, que têm menores índices de mobilidade (Pereira et al., 2010). 0 cordão de dunas é geralmente constituído por areias finas quartzosas (Martins, 1967), interrompidos por sangradouros, os quais são os grandes responsáveis pela descontinuidade do cordão de dunas frontais ao longo do litoral do RS. Do sul ao norte ocorrem uma média de 6 a 10 sangradouros a cada $10 \mathrm{~km}$, diminuindo para 4 nas proximidades da Laguna de Tramandaí, onde a drenagem é direcionada para este corpo d'água e, novamente, aumentando para 10 a 14 em direção a Torres (Figueiredo \& Calliari, 2005).

Em certos setores da costa, notam-se extensos campos de dunas que avançam sobre pântanos, e um conjunto de lagoas costeiras. A altura das dunas frontais aumenta gradativamente de norte para sul, sendo as maiores, encontradas no balneário de Dunas Altas (Palmares do Sul), com alturas entre 6 a $8 \mathrm{~m}$. Segundo a classificação de Hesp (1988), 50\% das dunas no litoral norte encontram-se no estágio 2 , sendo caracterizadas por topografias simples, lateralmente contínuas e com 75 a $90 \%$ de suas superfícies vegetadas (Calliari 
et al., 2005).

Sobre o litoral, incidem ondulações geradas longe da costa e vagas formadas pelos ventos locais. Segundo Strauch et al. (2009) as alturas significativas de ondas no verão em Tramandaí apresentam valores entre 1,5 e $3 \mathrm{~m}$ e as ondas são provenientes de ENE (leste-nordeste) e S (sul). No outono, as alturas significativas são de $4 \mathrm{~m}$ incidindo de ENE e S, com predominância da direção SSE (sul-sudeste). Os períodos de picos se dividem entre as direções ENE e S com valores de até $15 \mathrm{~s}$ na direção SE (sudeste), apresentando maior frequência na faixa de 9 a 12 s na mesma direção. No outono, os períodos de pico se distribuem entre as mesmas direções observadas no verão, atingindo valores de $19 \mathrm{~s}$ com predominância na direção SSE e apresentando frequências entre 9 a $12 \mathrm{~s}$.

A maré astronômica é semidiurna, com valores de amplitude máximos da ordem de 0,32 $\mathrm{m}$ e média de 0,30 m (Toldo Jr et al., 2006). De acordo com o mesmo autor, as marés meteorológicas positivas podem atingir três vezes o valor dos níveis de preamar normais para a região e, além de ocasionar elevação do nível do mar, podem causar o atraso ou adiantamento dos instantes de ocorrência das preamares e baixa-mares. As marés astronômicas positivas possuem maior influência e intensidade durante outono e primavera, o que torna estas estações períodos favoráveis ao aumento do nível do mar na costa. As marés meteorológicas (ressaca) podem alcançar 1,20 m (Almeida et al., 1997). As ressacas têm sido registradas com mais frequência nos meses de abril a maio, associadas a frentes frias (Tozzi, 1999; Barletta, 2001).

\subsection{Métodos}

Neste trabalho foram utilizados os dados brutos do Lidar, arquivos em formato ASCII referenciados ao sistema SIRGAS 2000 com altitudes referenciadas ao elipsóide (altitude geométrica). Esses arquivos foram processados no software ALDPAT versão 1.0 desenvolvido pelo Centro Internacional de Pesquisas em Furacões da Universidade Internacional da Flórida, (Zhang \& Zheng, 2007). Neste software foram produzidos modelos digitais de superfícies (MDS) a partir da nuvem de pontos provenientes do segundo pulso do Lidar. Os MDS foram produzidos a partir de uma malhar com 0,5 m e resolução pelo interpolador krigagem, de acordo com a metodologia de Robertson et al. (2004). Os MDS passaram por um processo de conversão de altitudes com o objetivo de se transformar as altitudes geométricas em ortométricas, referenciadas ao geóide, utilizando-se o modelo geoidal produzido por Gonçalves (2010).

0 recobrimento Lidar foi executado sobre todo o litoral norte do RS em julho de 2010. O Lidar utilizado foi o modelo ALTM 2050 da Optech. 0 recobrimento foi efetuado com altura de voo igual a $1000 \mathrm{~m}$, ângulo de escaneamento de $20^{\circ}$ e densidade de 2 pontos por $\mathrm{m}^{2}$. 0 levantamento atende o Padrão de Exatidão Cartográfico Classe A para a escala 1:2000, com precisão de $50 \mathrm{~cm}$ na planimetria e $15 \mathrm{~cm}$ na altimetria.

A metodologia utilizada para a extração das feições geomorfológicas (perfis praiais, posição da linha de costa e base da duna frontal) e cálculo dos parâmetros morfométricos de interesse (largura da praia subaérea, azimute da linha de costa, altura das dunas frontais e variação do volume do perfil) é descrita como segue.

Linha de costa: A linha de costa considerada foi a linha d'água, ou seja, o limite instantâneo do runup (Overton et al., 1999; Hoeke et al., 2001). Essa metodologia foi adaptada para o MDS de modo que a linha de costa foi considerada como a linha contínua que dá inicio à suave declividade da praia. Foi identificada e demarcada manualmente através da sobreposição de curvas de nível sobre classes de altitudes atribuídas ao MDS.

Base da duna: Consiste na quebra da suave declividade da praia para a brusca declividade da duna (Battiau-Queney et al., 2003). A metodologia para a identificação dessa feição se deu de modo semelhante à aplicada para a demarcação da linha de costa, porém, a base da duna é a primeira linha que dá inicio a um aumento brusco na declividade do perfil.

Variação do Volume acima do Datum (VVAD): Perfis transversais à linha de costa foram levantados sobre o MDS, em intervalos aproximados de $250 \mathrm{~m}$, com origem na linha de costa e prolongando-se até a crista da duna frontal. 0 cômputo do volume do perfil foi efetuado para uma faixa de 10 $\mathrm{m}$ de largura, com o perfil traçado sobre o MDS ao centro. A VVAD foi calculada dividindo-se o volume pela distância horizontal do perfil.

Largura da praia subaérea: Calculada sobre os perfis, é a distância horizontal medida entre a linha de costa até a base da duna frontal.

Declividade da praia subaérea: Consiste na subtração entre as altitudes da base da duna frontal e linha de costa dividida pela largura da praia subaérea. Esse parâmetro foi determinado para cada um dos perfis em percentagem (\%).

Altura das dunas: Foi computada para cada balneário, através do MDS, traçando-se um vetor sobre a crista de todas as dunas frontais da área de estudo. Esses vetores foram convertidos para 
arquivos ASCII para se determinar, em software de computação numérica, a altura média.

Orientação da linha de costa: Consiste no azimute de quadrícula da linha de costa calculado para todos os balneários da área de estudo.

Um exemplo de perfil com as marcações citadas anteriormente é apresentado na figura 2.

Parâmetros adicionais foram retirados da bibliografia, relacionados a seguir.

$\mathrm{Mz} \varphi$ (phi): Consiste no tamanho do grão médio $(\mathrm{Mz})$ na escala logarítmica de Wentworth (1922). É definido por $\mathrm{D}=\mathrm{d} 0 * 2-\varphi$, onde $\mathrm{D}$ é o diâmetro da partícula, d0 é igual a 1 e $\varphi=-\log 2$. Os valores de $\mathrm{Mz}$ utilizados nesse trabalho foram extraídos de Pereira et al. (2010).

Am (\%): Percentual de areia média (Am), segundo a escala Wentworth (1922). Corresponde ao percentual do diâmetro no intervalo de $1 / 4$ a $1 / 2$ mm ( 2 a 1 phi). Assim como o Mz, o Am foi extraído de Pereira et al. (2010).

Potencial de deriva de vento (PDV): Determinado a partir de dados médios de vento (direção e velocidade) obtidos de estações meteorológicas situadas em Torres, Imbé e Mostardas (Tomazelli, 1993). Os PDV foram calculados para cada estação por Martinho (2010), sendo publicados na forma de diagrama de rosa dos ventos. Os valores, em unidades de vetores (UV), dos PDV utilizados foram extraídos de Martinho et al. (2010).

Os valores de $\mathrm{Mz}$ e Am são pontuais, não abrangendo todos os balneários estudados. A solução encontrada para a ausência de dados foi a extrapolação dos valores para os balneários vizinhos, ou seja, foram adotados valores iguais para balneários com características morfométricas semelhantes.

Após a coleta, os dados citados foram organizados na forma de tabela para posterior análise estatística. Foram utilizadas técnicas de estatística multivariada exploratória, análise de escalo- namento multidimensional (AMDS) e de agrupamento (cluster). As análises foram efetuadas com o software PRIMER versão 5.2.4 (Clarke \& Gorley, 2006). A seguir é apresentada uma breve descrição das técnicas efetuadas, adaptado de Gray et. al. (1988) e Pereira et. al. (2010).

Segundo Manly (1994) o AMDS inicia com uma matriz distância entre $\mathbf{n}$ objetos, $\boldsymbol{\delta} \mathbf{i j}$, distância do objeto $\mathbf{i}$ para o $\mathbf{j}$, na linha i e coluna $\mathbf{j}$. 0 número de dimensões t para o mapeamento dos objetos é fixado por uma solução particular.

A interpretação do AMDS é diretamente efetuada no diagrama, ou seja, pontos agrupados próximos representam amostras que possuem variáveis ambientais muito similares e pontos que estão distantes correspondem a valores muito diferentes (Clarke \& Gorley, 2006). A partir dos agrupamentos de balneários no diagrama AMDS, foram criados grupos de praias com características comuns indicados pela sua proximidade no diagrama do AMDS. A significância estatística destes grupos foi avaliada com o teste ANOSIM ( $\mathrm{p}<0,05)$, (Clarke \& Gorley, 2006).

A técnica cluster utilizada no PRIMER gera uma árvore (dendograma) horizontal através de agrupamentos aglomerados hierarquicamente. Essa técnica adota uma matriz de similaridade como partida e, sucessivamente, funde as amostras em grupos e os grupos em grandes aglomerados e assim sucessivamente. 0 cluster inicia com a mais alta similaridade mútua e então, gradualmente, diminui o nível de similaridade dos quais os grupos são formados. No final, um único diagrama de agrupamento é obtido.

Os dados para a análise consistem de valores $\boldsymbol{Y 1}, \boldsymbol{Y 2}, \boldsymbol{Y 3}, \ldots, \boldsymbol{Y p}$ em função da variável $\boldsymbol{p}$ para $\mathbf{n}$ objetos. No caso de agrupamento hierárquico, os valores são usados para gerar uma matriz distância entre os indivíduos. A distância euclidiana pode ser calculada pela seguinte fórmula (Manly, 1994):

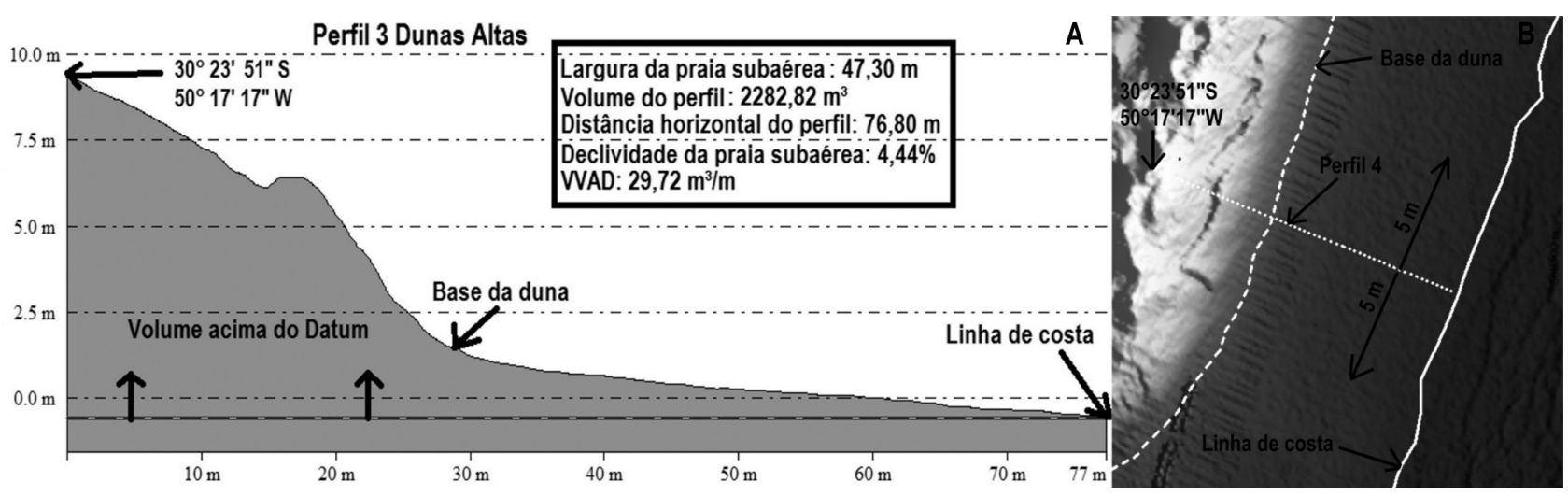

Figura 2. Vista em corte (A) e superior (B) de um perfil transversal esquemático com os principais parâmetros morfométricos levantados. 
distância.euclidiana $=\sum(Y i k-Y j k)^{2}$ onde : (1)

Na expressão (1) Yik é o valor da variável, Yk para o indivíduo i e Yjk é o valor da mesma variável de indivíduo $\mathbf{j}$.

É conveniente salientar que, antes do cálculo da matriz similaridade (matriz triangular) contendo a distância euclidiana entre os objetos, os dados foram transformados através da extração de suas raízes quadradas visando à padronização. Esse procedimento é necessário, visto que as variáveis possuem diferentes unidades de medida.

A cluster é gerada a partir de uma matriz de similaridade criada sobre as características ambientais de cada trecho de praia. Desta forma, as praias são classificadas entre si pelos critérios que as diferenciam ou aproximam através do Índice de Similaridade.

\section{Resultados}

Os parâmetros morfométricos dos diferentes municípios que constituem a área de estudo podem ser visualizados nas tabelas 1 (Palmares do Sul), 2 (Balneário Pinhal), 3 (Cidreira), 4 (Tramandaí), 5 (Imbé), 6 (Osório), 7 (Xangri-lá), 8 (Capão da Canoa), 9 (Terra de Areia), 10 (Arroio do Sal) e 11 (Torres).

Tabela 1. Parâmetros morfométricos do município de Palmares do Sul, praia de Quintão.

\begin{tabular}{ccccccccc}
\hline Balneários & Decliv.(\%) & $\begin{array}{c}\text { Largura } \\
\text { média }(\mathrm{m}) \\
\text { da praia } \\
\text { subaérea }\end{array}$ & $\begin{array}{c}\text { Var.vol } \\
\left(\mathrm{m}^{3} / \mathrm{m}\right)\end{array}$ & $\begin{array}{c}\text { Azimute } \\
\text { inha costa } \\
\text { (graus) }\end{array}$ & $\begin{array}{c}\text { Alt.dunas } \\
\text { frontais }(\mathrm{m})\end{array}$ & Mz (Phi) & Am (\%) & PDV \\
\hline Dunas Altas & 3,75 & 61,92 & 23,9 & 17,87 & 7,66 & 2,25 & 35 & 39,17 \\
Santa Rita & 2,91 & 61,33 & 15,8 & 16,31 & 6,76 & 2,25 & 35 & 39,17 \\
$\quad$ Frade & 3,15 & 56,31 & 18,76 & 17,59 & 6,01 & 2,25 & 35 & 39,17 \\
Rei do Peixe & 3,35 & 59,94 & 16,91 & 18,67 & 5,55 & 2,25 & 35 & 39,17 \\
$\quad \begin{array}{c}\text { Centro } \\
\text { (Pioneiros) }\end{array}$ & 3,1 & 58,67 & 16,72 & 18,69 & 4,99 & 2,25 & 35 & 39,17 \\
Campo Dunas & 3,34 & 55,47 & 12,1 & 19,55 & 4,57 & 2,25 & 35 & 39,17 \\
$\quad$ Média & 3,27 & 58,94 & 17,36 & 18,11 & 5,92 & 2,25 & 35 & 39,17 \\
\hline
\end{tabular}

Abreviações: Alt.dunas frontais (m)=Altura das dunas frontais em m; Am (\%)=Percentual de areia média em \%; B=Barra; $\mathrm{C}=$ Centro; $\mathrm{CCI}=$ Loteamento Companhia Comercial de Imóveis; $\mathrm{CD}=$ campo de dunas; Decliv.(\%)=declividade da praia subaérea em \%; JA=Jardim Atlântico; JE=Jardim do Édem; Mz (Phi)=Tamanho do grão médio em phi; NTA= Nova Tramandaí plano A; NTB= Nova Tramandaí plano B; OS=Oásis Sul; PDV=Potencial de deriva de vento em unidades de vetores (UV); TJ=Tiarajú; TS=Tramandaí Sul; Var.vol $\left(\mathrm{m}^{3} / \mathrm{m}\right)=$ Variação do Volume acima do Datum $\mathrm{em} \mathrm{m}^{3} / \mathrm{m}$; ZN=Zona Nova; ZNES= Zona Nova Extensão Sul; ZNS=Zona Nova Sul.

Tabela 2. Parâmetros morfométricos do município de Balneário Pinhal. Obs: para abreviações vide tabela 1.

\begin{tabular}{ccccccccc}
\hline Balneários & $\begin{array}{c}\text { Decliv. } \\
(\%)\end{array}$ & $\begin{array}{c}\text { Largura média } \\
\text { da praia } \\
\text { subaérea }(\mathrm{m})\end{array}$ & $\begin{array}{c}\text { Varvol } \\
\left(\mathrm{m}^{3} / \mathrm{m}\right)\end{array}$ & $\begin{array}{c}\text { Azimute } \\
\text { linha costa } \\
\text { (graus) }\end{array}$ & $\begin{array}{c}\text { Alt. dunas } \\
\text { frontais (m) }\end{array}$ & Mz (Phi) & Am (\%) & PDV \\
\hline $\begin{array}{c}\text { Rua Bagé } \\
\text { até Getúlio } \\
\text { Vargas }\end{array}$ & 2,46 & 65,9 & 12,44 & 20,32 & 6,52 & 2,24 & 25 & 39,17 \\
$\begin{array}{c}\text { Rua Venâncio } \\
\text { Aires ate } \\
\text { Tipio }\end{array}$ & 3,04 & 79,55 & 13,81 & 19,51 & 4,51 & 2,24 & 25 & 39,17 \\
$\begin{array}{c}\text { Av Brasil ate } \\
\text { Travessa 45 }\end{array}$ & 3,43 & 64,19 & 13,19 & 18,84 & 4,17 & 2,24 & 25 & 39,17 \\
$\begin{array}{c}\text { Travessa 43 } \\
\text { ate Av Pampa } \\
\text { Av Pampa } \\
\text { ate Av Jose } \\
\quad \text { Krauer }\end{array}$ & 5,16 & 36,49 & 14,6 & 18,33 & 4,85 & 2,24 & 25 & 39,17 \\
$\begin{array}{c}\text { Travessa São } \\
\text { Lucas ate Rua } \\
\text { Garça }\end{array}$ & 3,15 & 51,14 & 12,14 & 20,21 & 3,87 & 2,24 & 25 & 39,17 \\
$\quad$ & 87,16 & 13,55 & 18,9 & 3,39 & 2,24 & 25 & 39,17 \\
$\quad$ Média & 3,71 & 64,07 & 13,29 & 19,35 & 4,55 & 2,24 & 25 & 39,17 \\
\hline
\end{tabular}


Tabela 3. Parâmetros morfométricos dos balneários do município de Cidreira. Obs: para abreviações vide tabela 1.

\begin{tabular}{|c|c|c|c|c|c|c|c|c|}
\hline Balneários & $\begin{array}{c}\text { Decliv. } \\
(\%)\end{array}$ & $\begin{array}{l}\text { Largura média } \\
\text { da praia } \\
\text { subaérea }(\mathrm{m})\end{array}$ & $\begin{array}{l}\text { Var.vol } \\
\left(\mathrm{m}^{3} / \mathrm{m}\right)\end{array}$ & $\begin{array}{l}\text { Azimute } \\
\text { linha costa } \\
\text { (graus) }\end{array}$ & $\begin{array}{l}\text { Alt. dunas } \\
\text { frontais }(\mathrm{m})\end{array}$ & Mz (Phi) & Am (\%) & PDV \\
\hline Costa do Sol & 3,65 & 75,97 & 15,06 & 18,38 & 4,1 & 2,24 & 25 & 39,17 \\
\hline Zona A & 3,55 & 72,93 & 11,03 & 18,57 & 3,73 & 2,24 & 25 & 39,17 \\
\hline Centro & 4,42 & 60,54 & 11,47 & 19,3 & 4,26 & 2,24 & 25 & 39,17 \\
\hline Nazaré & 3,92 & 70,04 & 12,23 & 17,97 & 3,68 & 2,24 & 25 & 39,17 \\
\hline Salinas & 3,4 & 65,32 & 14,45 & 18,61 & 6,49 & 2,24 & 25 & 39,17 \\
\hline $\begin{array}{c}\text { Campo de } \\
\text { Dunas }\end{array}$ & 4,37 & 62,92 & 13,43 & 19,55 & 3,82 & 2,49 & 8 & 39,17 \\
\hline Média & 3,89 & 67,95 & 12,94 & 18,73 & 4,35 & 2,66 & 22,17 & 39,17 \\
\hline
\end{tabular}

Tabela 4. Parâmetros morfométricos dos balneários do município de Tramandaí. Obs: para abreviações vide tabela 1.

\begin{tabular}{ccccccccc}
\hline Balneários & Decliv. (\%) & $\begin{array}{c}\text { Largura média } \\
\text { da praia } \\
\text { subaérea }(\mathrm{m})\end{array}$ & $\begin{array}{c}\text { Var.vol } \\
\left(\mathrm{m}^{3} / \mathrm{m}\right)\end{array}$ & $\begin{array}{c}\text { Azimute linha } \\
\text { costa (graus) }\end{array}$ & $\begin{array}{c}\text { Alt. dunas } \\
\text { frontais } \\
(\mathrm{m})\end{array}$ & Mz (Phi) & Am (\%) & PDV \\
\hline CD & 3,5 & 68,92 & 13,68 & 19,87 & 5,67 & 2,49 & 8 & 39,17 \\
TJ & 2,96 & 74,6 & 15,09 & 19,92 & 5,44 & 2,49 & 8 & 39,17 \\
JE & 2,94 & 66,55 & 12,83 & 25,37 & 3,57 & 2,49 & 8 & 39,17 \\
JA & 3,86 & 78,63 & 12,19 & 27,09 & 3,22 & 2,49 & 8 & 39,17 \\
OS & 4,63 & 65,2 & 16,93 & 20,57 & 4,07 & 2,49 & 8 & 39,17 \\
NTB & 4,69 & 64,7 & 12,94 & 19,55 & 3,99 & 2,49 & 8 & 39,17 \\
NTA & 4,49 & 63,38 & 14,13 & 22,26 & 4,46 & 2,49 & 8 & 39,17 \\
TS & 3,71 & 78,37 & 12,88 & 20,79 & 3,37 & 2,49 & 8 & 39,17 \\
ZNES & 3,63 & 73,4 & 14,44 & 20,53 & 3,72 & 2,26 & 22 & 39,17 \\
ZNS & 4,36 & 59,77 & 12,58 & 21,97 & 4,19 & 2,26 & 22 & 39,17 \\
ZN & 3,9 & 64,16 & 12,64 & 21,62 & 4,27 & 2,26 & 22 & 39,17 \\
C & 5,59 & 39,53 & 9,67 & 19,77 & 4,23 & 2,26 & 22 & 39,17 \\
B & 7,04 & 42,62 & 22,48 & 24,65 & 6,31 & 2,26 & 22 & 39,17 \\
Média & 4,25 & 64,6 & 14,04 & 21,84 & 4,35 & 2,42 & 13,38 & 39,17 \\
\hline
\end{tabular}

Tabela 5. Parâmetros morfométricos dos balneários do município de Imbé. Obs: para abreviações vide tabela 1.

\begin{tabular}{ccccccccc}
\hline Balneários & $\begin{array}{c}\text { Decliv. } \\
(\%)\end{array}$ & $\begin{array}{c}\text { Largura média da } \\
\text { praia subaérea } \\
(\mathrm{m})\end{array}$ & $\begin{array}{c}\text { Var.vol } \\
\left(\mathrm{m}^{3} / \mathrm{m}\right)\end{array}$ & $\begin{array}{c}\text { Azimute } \\
\text { linha de } \\
\text { costa } \\
\text { (graus) }\end{array}$ & $\begin{array}{c}\text { Alt.dunas } \\
\text { frontais }(\mathrm{m})\end{array}$ & Mz (Phi) & Am (\%) & PDV \\
\hline Balneário Imbé & 4,43 & 47,67 & 9,64 & 24,16 & 6,88 & 2,19 & 30 & 39,17 \\
Ecademar & 2,55 & 56,25 & 10,33 & 18,14 & 3,81 & 2,19 & 30 & 39,17 \\
Morada do Sol & 2,84 & 49,26 & 21,91 & 23,30 & 4,17 & 2,19 & 30 & 39,17 \\
Presidente & 2,56 & 54,6 & 13,39 & 23,66 & 4,02 & 2,19 & 30 & 39,17 \\
Riviera & 2,73 & 51,3 & 19,34 & 21,5 & 5,01 & 2,19 & 30 & 39,17 \\
Ipiranga & 2,39 & 58,7 & 15,18 & 21,92 & 5,18 & 2,19 & 30 & 39,17 \\
Nordeste & 3,44 & 50,89 & 15,18 & 28,07 & 4,9 & 2,19 & 30 & 39,17 \\
Mariluz & 2,86 & 66,85 & 18,19 & 19,15 & 5,23 & 2,19 & 30 & 39,17 \\
Mariluz plano B & 3,74 & 49,41 & 15,56 & 25,77 & 5,37 & 2,19 & 30 & 39,17 \\
Mariluz plano C & 3,09 & 60 & 11,71 & 20,87 & 4,37 & 2,19 & 30 & 39,17 \\
Harmonia & 2,83 & 56,45 & 11,69 & 21,51 & 3,6 & 2,19 & 30 & 39,17 \\
Mariluz Norte & 3,2 & 42,55 & 13,27 & 22,96 & 5,02 & 2,19 & 30 & 39,17 \\
Albatroz & 3,03 & 44,58 & 10,5 & 23,33 & 4,15 & 2,19 & 30 & 39,17 \\
Marisul & 2,45 & 55,2 & 10,11 & 21,7 & 4,07 & 2,19 & 30 & 39,17 \\
Santa Terezinha & 2,28 & 59,525 & 14,68 & 24,04 & 3,64 & 2,19 & 30 & 39,17 \\
Santa Terezinha & 3,05 & 44,82 & 14,11 & 23,32 & 3,67 & 2,19 & 30 & 39,17 \\
Norte & & & & & & & 3,19 \\
Imara & 3,67 & 36,35 & 12,31 & 23,48 & 4,66 & 2,19 & 30 & 39,17 \\
Média & 3 & 52,03 & 13,95 & 22,76 & 4,57 & 2,19 & 30 & 39,17 \\
\hline
\end{tabular}


Tabela 6. Parâmetros morfométricos dos balneários do município de Osório. Obs: para abreviações vide tabela 1.

\begin{tabular}{ccccccccc}
\hline Balneários & $\begin{array}{c}\text { Decliv. } \\
(\%)\end{array}$ & $\begin{array}{c}\text { Largura média } \\
\text { da praia } \\
\text { subaérea (m) }\end{array}$ & $\begin{array}{c}\text { Var.vol } \\
\left(\mathrm{m}^{3} / \mathrm{m}\right)\end{array}$ & $\begin{array}{c}\text { Azimute } \\
\text { linha de } \\
\text { costa } \\
\text { (graus) }\end{array}$ & $\begin{array}{c}\text { Alt.dunas } \\
\text { frontais (m) }\end{array}$ & Mz (Phi) & Am (\%) & PDV \\
\hline Atlântida Sul & 3,33 & 32,16 & 13,3 & 23,22 & 4,44 & 2,09 & 45 & 39,17 \\
Mariápolis & 3,33 & 54,97 & 11,56 & 22,87 & 4,26 & 2,09 & 45 & 39,17 \\
Média & 3,33 & 43,56 & 12,43 & 23,04 & 4,35 & 2,09 & 45 & 39,17 \\
\hline
\end{tabular}

Tabela 7. Parâmetros morfométricos dos balneários do município de Xangri-lá. Obs: para abreviações vide tabela 1.

\begin{tabular}{ccccccccc}
\hline Balneários & $\begin{array}{c}\text { Decliv. } \\
(\%)\end{array}$ & $\begin{array}{c}\text { Largura média } \\
\text { da praia } \\
\text { subaérea }(\mathrm{m})\end{array}$ & $\begin{array}{c}\text { Var.vol } \\
\left(\mathrm{m}^{3} / \mathrm{m}\right)\end{array}$ & $\begin{array}{c}\text { Azimute } \\
\text { linha de } \\
\text { costa } \\
\text { (graus) }\end{array}$ & $\begin{array}{c}\text { Alt. } \\
\text { dunas } \\
\text { frontais } \\
(\mathrm{m})\end{array}$ & Mz (Phi) & Am (\%) & PDV \\
Xangri-Lá & 3,58 & 44,79 & 12,59 & 25,13 & 4,48 & 2,09 & 45 & 20 \\
CCI & 3,19 & 42,3 & 12,14 & 20,86 & 3,57 & 2,09 & 45 & 20 \\
Enara & 3,19 & 42,13 & 11,13 & 27,82 & 3,52 & 2,09 & 45 & 20 \\
Atlântida & 3,23 & 57,86 & 11,84 & 24,37 & 4,03 & 2,09 & 45 & 20 \\
Média & 3,3 & 46,77 & 11,93 & 24,54 & 3,9 & 2,09 & 45 & 20 \\
\hline
\end{tabular}

Tabela 8. Parâmetros morfométricos dos balneários do município de Capão da Canoa. Obs: para abreviações vide tabela 1.

\begin{tabular}{|c|c|c|c|c|c|c|c|c|}
\hline Balneários & $\begin{array}{l}\text { Decliv. } \\
(\%)\end{array}$ & $\begin{array}{l}\text { Largura média } \\
\text { da praia } \\
\text { subaérea }(\mathrm{m})\end{array}$ & Var.vol $\left(\mathrm{m}^{3} / \mathrm{m}\right)$ & $\begin{array}{c}\text { Azimute } \\
\text { linha costa } \\
\text { (graus) } \\
\end{array}$ & $\begin{array}{c}\text { Alt.dunas } \\
\text { frontais (m) }\end{array}$ & Mz (Phi) & $\begin{array}{l}\mathrm{Am} \\
(\%)\end{array}$ & PDV \\
\hline Navegantes & 3,08 & 53,5 & 12,95 & 25 & 3,79 & 2,22 & 27 & 20 \\
\hline Centro & 3 & 55,95 & 10,62 & 24,83 & 4,21 & 2,22 & 27 & 20 \\
\hline Zona Nova & 3,95 & 42,58 & 12,32 & 26,21 & 3,82 & 2,22 & 27 & 20 \\
\hline Araça & 3,19 & 43,29 & 11,05 & 26,13 & 3,53 & 2,22 & 27 & 20 \\
\hline Arco Íris & 3,53 & 42,35 & 9,78 & 26,66 & 3,25 & 2,22 & 27 & 20 \\
\hline Guarani & 3,86 & 46,8 & 10,26 & 26,22 & 3,29 & 2,22 & 27 & 20 \\
\hline Zona Norte & 3,6 & 49,99 & 12,71 & 26,58 & 3,66 & 2,22 & 27 & 20 \\
\hline $\begin{array}{c}\text { Jardim Beira } \\
\text { Mar }\end{array}$ & 3,48 & 53,58 & 10,69 & 26,78 & 3,35 & 2,22 & 27 & 20 \\
\hline Praia do Barco & 3,31 & 50,86 & 11,68 & 26,42 & 4,06 & 2,22 & 27 & 20 \\
\hline Capão Novo & 3,76 & 45,78 & 12,82 & 27,46 & 3,81 & 2,22 & 27 & 20 \\
\hline Arroio Teixeira & 3,49 & 51,55 & 12,29 & 28,78 & 3,94 & 2,22 & 27 & 20 \\
\hline Conceição & 1,46 & 133,8 & 1,46 & 24,92 & 3,53 & 2,22 & 27 & 20 \\
\hline $\begin{array}{c}\text { Arroio Teixeira } \\
\text { Gleba B }\end{array}$ & 3,26 & 60,85 & 14,95285214 & 28,87 & 3,66 & 2,22 & 27 & 20 \\
\hline Curumin & 3,12 & 55,9 & 11,03 & 28,18 & 3,67 & 2,22 & 27 & 20 \\
\hline Média & 3,29 & 57,15 & 11,71 & 27,45 & 3,67 & 2,22 & 27 & 20 \\
\hline
\end{tabular}

Tabela 9. Parâmetros morfométricos dos balneários do município de Terra de Areia. Obs: para abreviações vide tabela 1.

\begin{tabular}{ccccccccc}
\hline Balneários & $\begin{array}{c}\text { Decliv. } \\
(\%)\end{array}$ & $\begin{array}{c}\text { Largura } \\
\text { média } \\
\text { da praia } \\
\text { subárea } \\
(\mathrm{m})\end{array}$ & $\begin{array}{c}\text { Var.vol } \\
\left(\mathrm{m}^{3} / \mathrm{m}\right)\end{array}$ & $\begin{array}{c}\text { Azimute linha } \\
\text { costa (graus) }\end{array}$ & $\begin{array}{c}\text { Alt. dunas } \\
\text { frontais (m) }\end{array}$ & Mz (Phi) & Am (\%) & PDV \\
\hline $\begin{array}{c}\text { Terra de } \\
\text { Areia }\end{array}$ & 3,18 & 53,18 & 11,54 & 30,17 & 3,56 & 2,22 & 27 & 20 \\
\hline
\end{tabular}


Tabela 10. Parâmetros morfométricos dos balneários do município de Arroio do Sal. Obs: para abreviações vide tabela 1.

\begin{tabular}{|c|c|c|c|c|c|c|c|c|}
\hline Balneários & $\begin{array}{l}\text { Decliv. } \\
(\%)\end{array}$ & $\begin{array}{l}\text { Largura } \\
\text { média } \\
\text { da praia } \\
\text { subaérea } \\
\text { (m) }\end{array}$ & $\begin{array}{c}\text { Var.vol } \\
\left(\mathrm{m}^{3} / \mathrm{m}\right)\end{array}$ & $\begin{array}{l}\text { Azimute } \\
\text { linha costa } \\
\text { (graus) }\end{array}$ & $\begin{array}{l}\text { Altura dunas } \\
\text { frontais }(\mathrm{m})\end{array}$ & Mz (Phi) & Am (\%) & PDV \\
\hline $\begin{array}{c}\text { Rua Santa Cruz } \\
\text { até Manoel } \\
\text { Alves Pereira }\end{array}$ & 3,15 & 65,05 & 11,13 & 31,7762 & 3,91 & 2,22 & 27 & 20 \\
\hline $\begin{array}{l}\text { Rua Castelo } \\
\text { Branco até } \\
\text { Amazonas }\end{array}$ & 3,06 & 66,6 & 11,79 & 31,7316 & 3,36 & 2,22 & 27 & 20 \\
\hline $\begin{array}{c}\text { Rua Amazonas } \\
\text { até Av. Assis } \\
\text { Brasil }\end{array}$ & 2,85 & 59,2 & 9,81 & 33,01 & 3,4 & 2,22 & 27 & 20 \\
\hline $\begin{array}{l}\text { Av Assis Brasil } \\
\text { até Rua Vinte e } \\
\text { Cinco de Abril }\end{array}$ & 3,52 & 55,95 & 11,75 & 33,01 & 3,53 & 2,22 & 27 & 20 \\
\hline $\begin{array}{c}\text { Rua A até } \\
\text { Tancredo Neves }\end{array}$ & 3,01 & 50,93 & 11,47 & 33,53 & 3,33 & 2,22 & 27 & 20 \\
\hline $\begin{array}{l}\text { Rua Tancredo } \\
\text { Neves até D }\end{array}$ & 3,03 & 67,26 & 10,98 & 32,54 & 3,06 & 2,22 & 27 & 20 \\
\hline Rua D até S & 3,67 & 48,92 & 11,29 & 30,38 & 2,76 & 2,22 & 27 & 20 \\
\hline $\begin{array}{l}\text { Rua A até Rua } \\
\text { Farroupilha }\end{array}$ & 3,39 & 49,62 & 10,6 & 33,34 & 3,41 & 2,22 & 27 & 20 \\
\hline $\begin{array}{c}\text { Rua } H \text { até } 1425 \\
\text { Brasília }\end{array}$ & 3,59 & 55,66 & 10,69 & 34,13 & 3,98 & 2,22 & 27 & 20 \\
\hline $\begin{array}{l}\text { Rua dos Ventos } \\
\text { até Farroupilha }\end{array}$ & 3,71 & 55,3 & 10,63 & 34,4 & 3,71 & 2,22 & 27 & 20 \\
\hline Média & 3,3 & 57,45 & 11,01 & 32,78 & 3,45 & 2,22 & 27 & 20 \\
\hline
\end{tabular}

\subsection{Análise estatística}

Primeiramente, todas as tabelas citadas, com os parâmetros morfométricos dos municípios, foram integradas em uma única tabela, para a aplicação das técnicas de estatísticas descritas na metodologia. A utilização da técnica cluster para as oito variáveis apresentadas resultou na matriz de distâncias euclidianas e no dendrograma.

A formação dos grupos foi efetuada com a adoção de uma linha de corte na distância euclidiana 0,85 . A adoção dessa distância não é arbitrária e se deu a partir do conhecimento prévio da área de estudo e com o auxilio de trabalhos anteriores, como o de Pereira et al. (2010) que encontrou seis grupos de similaridade para a costa do RS. No dendrograma da figura 3, quatro grupos foram formados com a técnica cluster.

Os grupos formados são constituídos por trechos de praia contínuos, sendo o grupo 1 iniciado em Dunas Altas prolongando-se até Salinas, onde é interrompido pelo grupo 4 que abrange o setor entre o campo de dunas de Tramandaí até Tramandaí Sul. 0 grupo 1 reinicia na Zona Nova extensão Sul (Tramandaí) seguindo até Mariápolis (Osório), com exceção da Barra de Tramandaí. 0 grupo 2 estende-se do limite sul de Xangri-lá até o limite norte de Arroio do Sal, com exceção de Conceição (Capão da Canoa). Também faz parte desse grupo, a Praia da Cal. A inclusão dessa praia no grupo 2 se deu pelo percentual de areia média e azimute da linha de costa, valores muito próximos aos das praias desse grupo. 0 grupo 3 é constituído pelos balneários do município de Torres, Paraíso até Praia Grande, com exceção da Praia da Cal, Prainha e Parque Nacional da Guarita.

Quatro praias (Fig. 3) não pertencem a nenhum dos grupos formados por apresentarem valores dos parâmetros morfométricos muitos distintos das demais, discriminadas a seguir.

Parque Nacional da Guarita: A não inclusão dessa praia, pertencente ao município de Torres, em nenhum grupo, pode ser atribuída ao grande azimute da linha de costa, próximo a $70^{\circ}$, responsável pelo aumento da distância euclidiana em relação às demais praias.

Prainha: Praia pertencente a Torres não incluída em nenhum grupo em função de diferentes parâmetros morfométricos e geológicos que a diferencia das demais, como Am e pela reduzida altura das dunas frontais.

Conceição: Corresponde a uma faixa de praia de aproximadamente $255 \mathrm{~m}$ no município de Capão da Canoa, com cordão de dunas interrompido 
Tabela 11. Parâmetros morfométricos dos balneários do município de Torres. Obs: para abreviações vide tabela 1.

\begin{tabular}{|c|c|c|c|c|c|c|c|c|}
\hline Balneários & $\begin{array}{l}\text { Decliv. } \\
\text { (\%) }\end{array}$ & $\begin{array}{c}\text { Largura } \\
\text { média } \\
\text { da praia } \\
\text { subaérea } \\
\text { (m) }\end{array}$ & $\begin{array}{l}\text { Var.vol } \\
\left(\mathrm{m}^{3} / \mathrm{m}\right)\end{array}$ & $\begin{array}{l}\text { Azimute } \\
\text { linha costa } \\
\text { (graus) }\end{array}$ & $\begin{array}{l}\text { Altura dunas } \\
\text { frontais (m) }\end{array}$ & Mz (Phi) & Am (\%) & PDV \\
\hline Paraíso & 3,09 & 49,14 & 10,92 & 35,24 & 3,33 & 2,28 & 7 & 20 \\
\hline Real & 3,04 & 50,56 & 11,02 & 34,95 & 3,84 & 2,28 & 7 & 20 \\
\hline Estrela do Mar & 4,21 & 45,28 & 12,14 & 35,37 & 3,46 & 2,28 & 7 & 20 \\
\hline Santa Helena & 4,43 & 40,96 & 9,39 & 35,84 & 3,4 & 2,28 & 7 & 20 \\
\hline Webber & 3,49 & 51,69 & 10,65 & 35,57 & 3,76 & 2,28 & 7 & 20 \\
\hline Recreio & 3,39 & 53,1 & 8,74 & 35 & 3,78 & 2,28 & 7 & 20 \\
\hline Petrópolis & 3,52 & 51,1 & 13,98 & 33,93 & 3,72 & 2,28 & 7 & 20 \\
\hline Yara & 3,85 & 47,51 & 13,57 & 35,05 & 3,83 & 2,28 & 7 & 20 \\
\hline Gaúcha Anexo & 4,15 & 43,33 & 14,11 & 32,95 & 3,97 & 2,28 & 7 & 20 \\
\hline Gaúcha & 2,8 & 69,2 & 9,03 & 37,11 & 3,65 & 2,28 & 7 & 20 \\
\hline Casqueiro & 2,99 & 65,3 & 10,52 & 35,29 & 3,65 & 2,28 & 7 & 20 \\
\hline Tupynambá & 3,16 & 61,7 & 9,54 & 32,29 & 3,4 & 2,28 & 7 & 20 \\
\hline Praia Riviera & 2,82 & 71,85 & 10,9 & 37,45 & 3,46 & 2,28 & 7 & 20 \\
\hline $\begin{array}{l}\text { Condomínio } \\
\text { Ocean Side }\end{array}$ & 4,04 & 48,24 & 12,11 & 34,48 & 3,65 & 2,28 & 7 & 20 \\
\hline $\begin{array}{l}\text { Lagoa do } \\
\text { Jardim }\end{array}$ & 2,77 & 70,3 & 9,2 & 39,93 & 3,17 & 2,28 & 7 & 20 \\
\hline Itapeva Sul & 2,9 & 67,3 & 10,43 & 28,57 & 3,28 & 2,28 & 7 & 20 \\
\hline Torres Tur & 3,29 & 59,2 & 11,84 & 33,56 & 3,18 & 2,28 & 7 & 20 \\
\hline $\begin{array}{l}\text { Itapeva III } \\
\text { Etapa }\end{array}$ & 3,2 & 61 & 13,08 & 34,55 & 3,75 & 2,28 & 7 & 20 \\
\hline Itapeva & 3,24 & 56,1 & 11,76 & 36,64 & 3,55 & 2,28 & 7 & 20 \\
\hline $\begin{array}{c}\text { Parque } \\
\text { Estadual de } \\
\text { Itapeva }\end{array}$ & 3,52 & 50,24 & 11,9 & 36,82 & 4,11 & 2,28 & 7 & 20 \\
\hline $\begin{array}{c}\text { Parque } \\
\text { Nacional da } \\
\text { Guarita }\end{array}$ & 4,93 & 38,6 & 6,69 & 69,8 & 4,82 & 2,28 & 7 & 20 \\
\hline Praia da Cal & 4,37 & 32,28 & 12,42 & 26,84 & 3,14 & 2,29 & 21 & 20 \\
\hline Prainha & 4,45 & 35,23 & 6,7 & 35,68 & 1,79 & 2,18 & 9 & 20 \\
\hline Praia Grande & 3,49 & 61,24 & 13,47 & 32,92 & 4,06 & 2,28 & 7 & 20 \\
\hline Média & 3,55 & 53,35 & 11 & 36,08 & 3,57 & 2,28 & 8 & 20 \\
\hline
\end{tabular}

por um grande sangradouro, responsável por aumentar a largura da praia subaérea e diminuir a declividade da mesma.

Barra: Praia ao sul do rio Tramandaí divisa entre os municípios de Tramandaí e Imbé. É diferenciada das praias vizinhas pela sua declividade, aproximadamente $7 \%$ e pela grande VVAD, próxima $22,5 \mathrm{~m}^{3} / \mathrm{m}$.

Para a aplicação da técnica AMDS, nomeou-se as praias como pertencentes aos grupos de 1 a 4, de acordo com os agrupamentos previamente observados pela análise cluster. A adoção desse procedimento permite uma boa visualização da distribuição das praias no gráfico. Os grupos sugeridos por essa análise (Fig. 4) pouco diferiram dos obtidos pela cluster.

Os pontos próximos representam praias com variáveis ambientais semelhantes. Na figura 4, a leitura do equivalente numérico para algumas praias não é possível em função da grande similaridade entre as mesmas, sinalizando que o agrupamento dessas praias é coerente.

As praias da Barra (Tramandaí), Conceição, Prainha e Parque Nacional da Guarita encontram-se distantes dos grupos apresentados (Fig. 4), confirmando os resultados encontrados na análise cluster. Com o objetivo de simplificar as discussões, essas praias foram consideradas pertencentes aos grupos que mais se aproximaram (Fig. 4). Os grupos sugeridos pela cluster e AMDS podem ser visualizados na figura 5 .

Imagens de hipsometria dos balneários que apresentam características representativas de cada um dos grupos podem ser visualizadas na figura 6 (grupo 1, Dunas Altas - Palmares do sul), na figura 7 (grupo 2, Capão Novo - Capão da Canoa), 
na figura 8 (grupo 3, Parque Estadual de Itapeva Torres) e na figura 9 (grupo 4 Campo de Dunas de Tramandaí).

Destaque especial foi dado ao grupo 1 (Fig. 6), que apresenta feições morfológicas únicas na área de estudo, geradas pelo vento predominante $\mathrm{NE}$, onde trailing ridges (rastros lineares), dunas parabólicas e blowouts são feições presentes. Uma característica marcante nesse balneário é a geomorfologia das dunas frontais contínuas e retilinizada com alturas superiores a $10 \mathrm{~m}$. Sangradouros segmentam as dunas frontais, em alguns pontos, transformando-as em segmentos mais curtos, sob a forma de massa isolada na forma de U com extremidades voltadas ao continente pela ação do vento NE.

O teste ANOSIM (análise de variância de similaridades) foi aplicado para avaliar possíveis diferenças significativas entre os grupos de praias encontrados. 0 teste demonstrou que o nível de significância global entre os grupos foi de 0,1\%. 0 valor $\mathrm{R}$ informa se os grupos foram bem formados quando os valores são próximos de 1 , com $\mathrm{R}$ calculado igual a 0,934 . Uma comparação entre todos os grupos pode ser visualizada na tabela 12 .

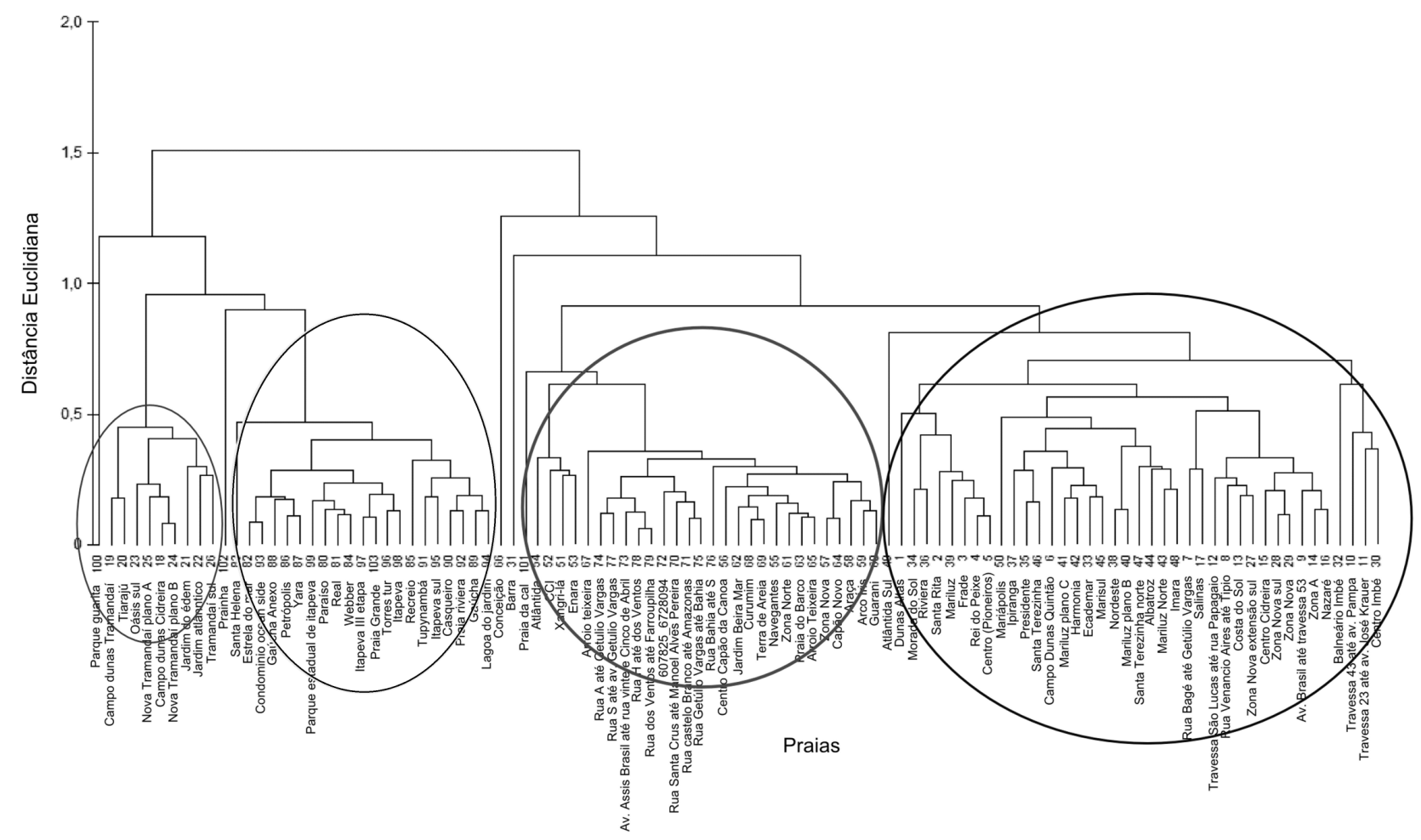

Figura 3. Dendrograma gerado a partir da análise Cluster, onde se observa a formação de quatro grupos de praias de maior similaridade.

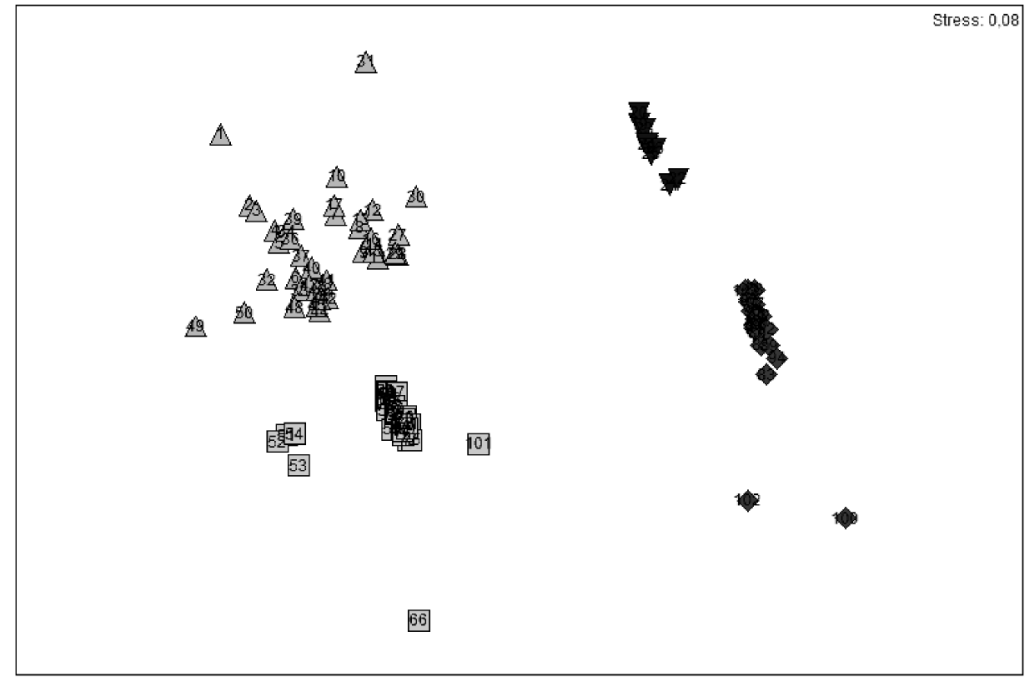

$\triangle$

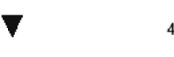

$\square$

Figura 4. Forma gráfica da análise de Escalonamento Multidimensional (AMDS), onde se observa a formação de quatro grupos de afinidade. 


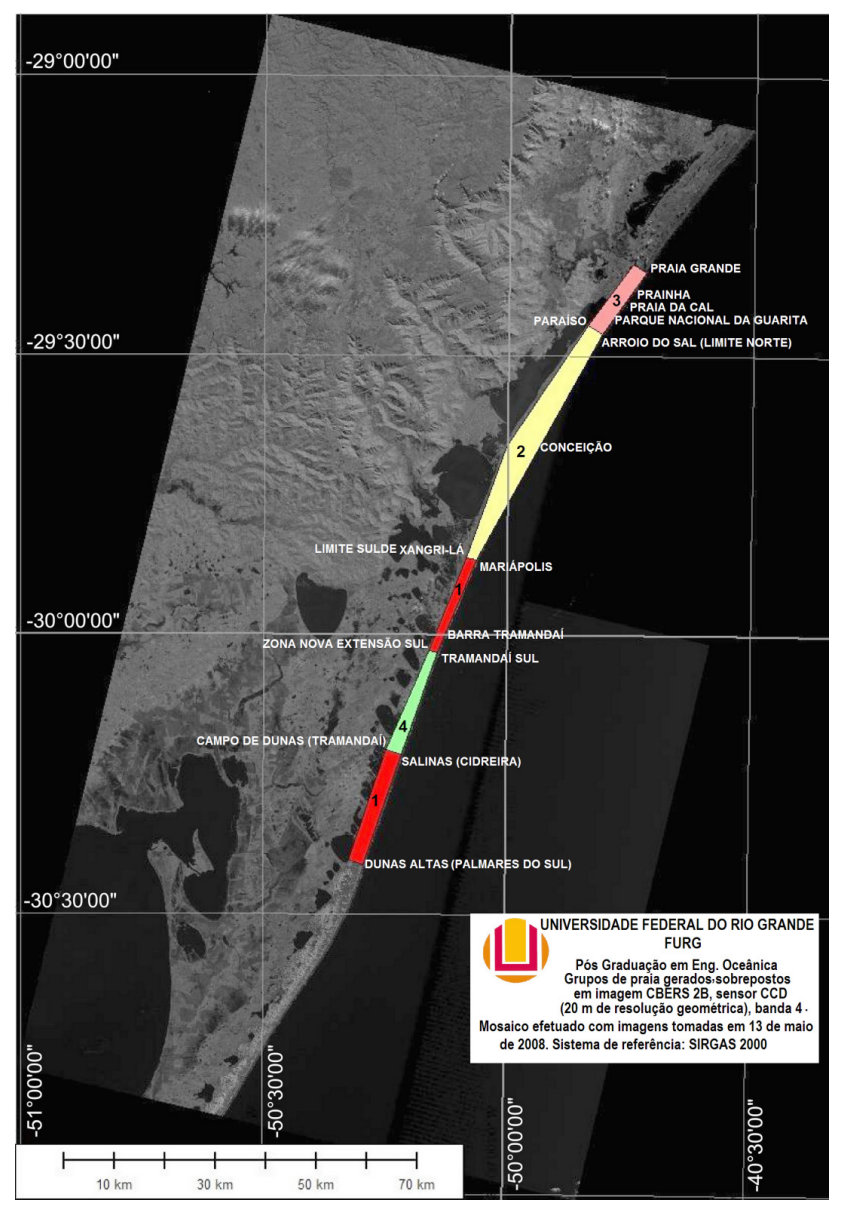

Figura 5. Imagem de satélite onde se observa a distribuição dos quatros grupos de praias formados nas análises cluster e MDS.

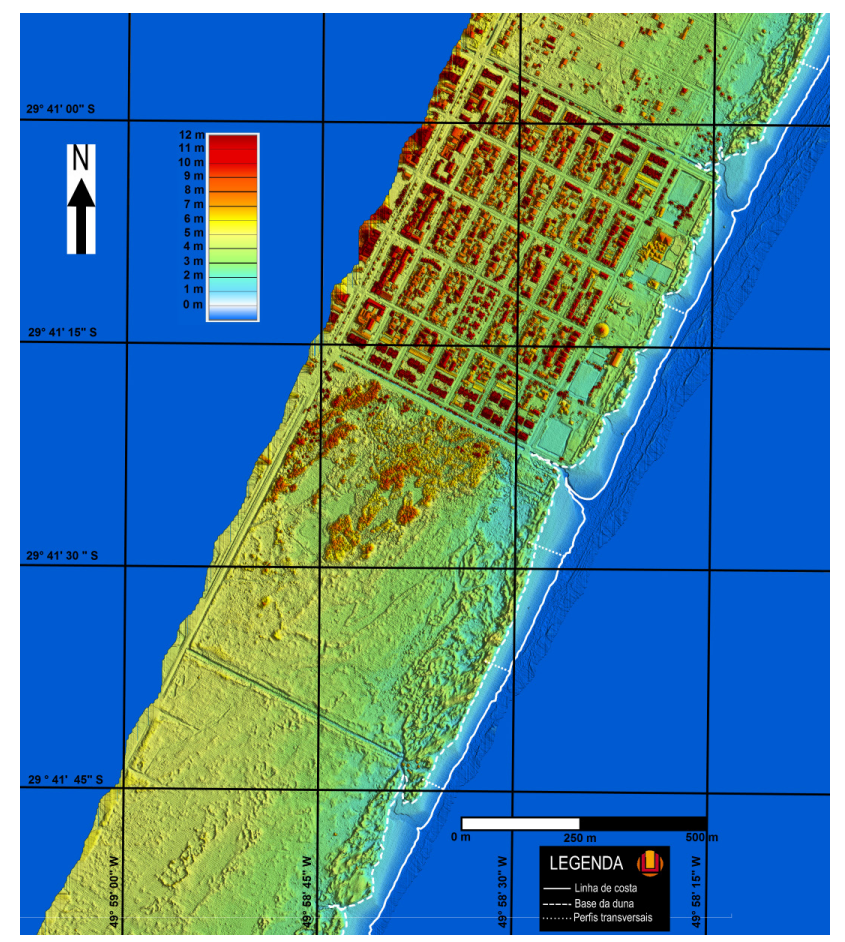

Figura 7. Hipsometria do balneário Capão Novo (Capão da Canoa).

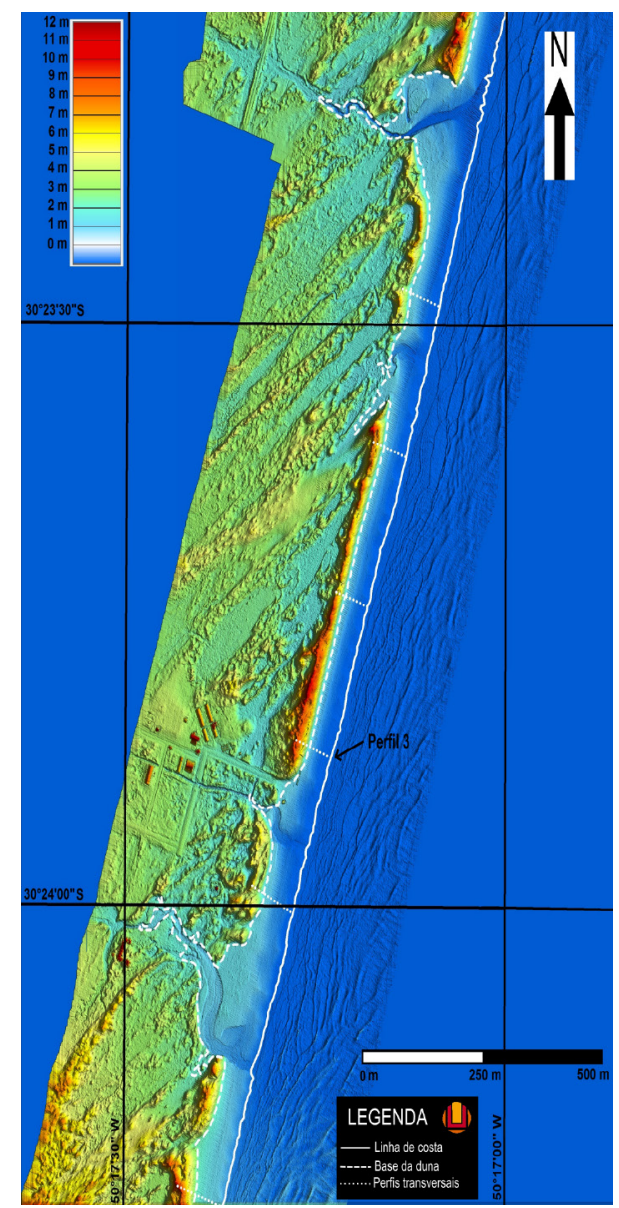

Figura 6. Hipsometria do balneário Dunas Altas (Palmares do Sul).

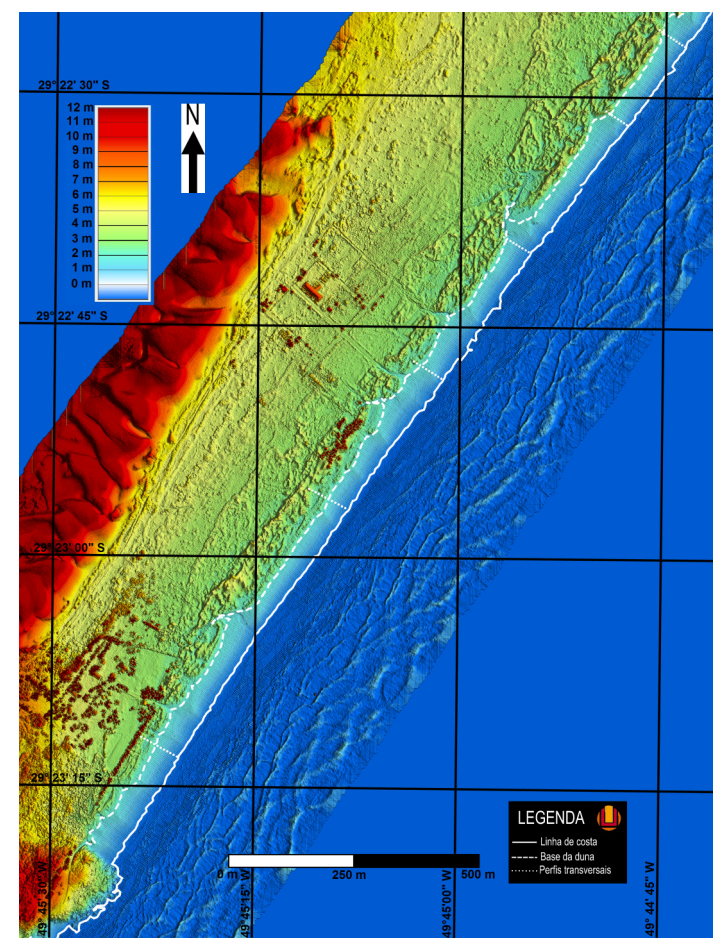

Figura 8. Hipsometria do Parque Estadual de Itapeva (Torres). 


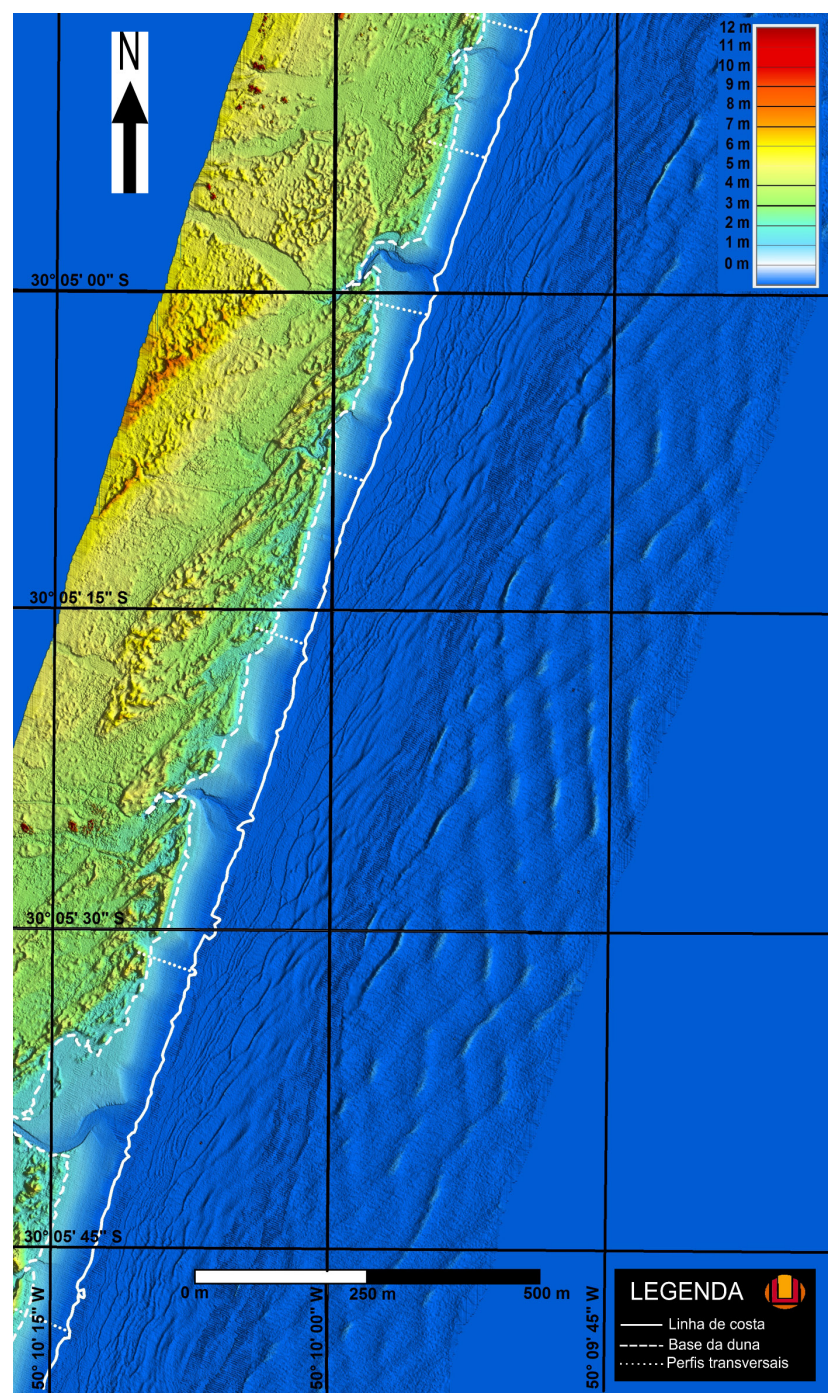

Figura 9. Hipsometria do campo de dunas de Tramandaí.

Tabela 12. Valores do R estatístico e nível de significância encontrado pelo ANOSIM para os grupos sugeridos

\begin{tabular}{ccc}
\hline Grupos & R estatístico & $\begin{array}{c}\text { Nível de significância } \\
(\%)\end{array}$ \\
\hline 1,4 & 0,99 & $-0,1$ \\
1,2 & 0,83 & 0,1 \\
1,3 & 1 & 0,1 \\
4,2 & 0,995 & 0,1 \\
4,3 & 0,85 & 0,1 \\
2,3 & 0,988 & 0,1 \\
\hline
\end{tabular}

O teste SIMPER (percentual de similaridade) examina a contribuição de cada variável ambiental para a formação dos grupos e diferenciação (dissimilaridade) dos mesmos. Nas tabelas 13 a 16 são apresentados os resultados de média e percentual de contribuição de cada uma das variáveis para a formação dos grupos.

As variáveis que mais contribuíram para a formação dos grupos foram: largura média da praia subaérea, PDV, azimute da linha de costa, Am e VVAD. As variáveis que menos contribuíram em todos os grupos foram a altura das dunas frontais, declividade média e Mz.

0 teste SIMPER gerou tabelas comparando todos os grupos contendo o percentual de contribuição de cada uma das variáveis ambientais para a dissimilaridade (diferença entre os grupos), com resultados apresentados na tabela 17.

Tabela 13. Média e percentual de contribuição das variáveis para a formação do grupo 1.

\begin{tabular}{lcc}
\hline Variáveis & Média & Contribuição (\%) \\
\hline Largura praia subaérea (m) & 56,92 & 18,93 \\
PDV & 39,17 & 17,85 \\
Am (\%) & 29,15 & 15,95 \\
Azimute linha costa (graus) & 20,96 & 14,58 \\
VVAD (m $\left.{ }^{3} / \mathrm{m}\right)$ & 14,19 & 12,48 \\
Altura dunas frontais (m) & 4,74 & 7,91 \\
Declividade (\%) & 3,49 & 6,68 \\
Mz (phi) & 2.22 & 1.40 \\
\hline
\end{tabular}

Abreviações: Am (\%)=Percentual de areia média em \%; Mz (Phi)=Tamanho do grão médio em phi; PDV=Potencial de deriva de vento em unidades de vetores (UV); VVAD= Variação do Volume acima do Datum em $\mathrm{m}^{3} / \mathrm{m}$.

Tabela 14. Média e percentual de contribuição das variáveis para a formação do grupo 2 .

\begin{tabular}{lcc}
\hline Variáveis & Média & Contribuição (\%) \\
\hline Largura praia subaérea (m) & 54,46 & 19,28 \\
Am (\%) & 29,2 & 16,56 \\
Azimute linha costa (graus) & 28,54 & 16,56 \\
PDV & 20,00 & 15,17 \\
VVAD (m $\left.{ }^{3} / \mathrm{m}\right)$ & 11,55 & 12,36 \\
Altura dunas frontais (m) & 3,61 & 7,38 \\
Declividade (\%) & 3,33 & 6,97 \\
Mz (phi) & 2.21 & 1.56 \\
\hline
\end{tabular}

Abreviações: Am (\%)=Percentual de areia média em \%; Mz (Phi)=Tamanho do grão médio em phi; PDV=Potencial de deriva de vento em unidades de vetores (UV); VVAD= Variação do Volume acima do Datum $\mathrm{em}^{3} / \mathrm{m}$.

Tabela 15. Média e percentual de contribuição das variáveis para a formação do grupo 3.

\begin{tabular}{lcc}
\hline Variáveis & Média & Contribuição (\%) \\
\hline Largura praia subaérea (m) & 54,27 & 20,45 \\
Azimute linha costa (graus) & 36,48 & 18,70 \\
PDV & 20,00 & 16,04 \\
VVAD (m³ $/ \mathrm{m})$ & 10,94 & 12,43 \\
Am (\%) & 7,09 & 10,96 \\
Altura dunas frontais (m) & 3,59 & 7,66 \\
Declividade (\%) & 3,51 & 7,51 \\
Mz (phi) & 2.28 & 1.78 \\
\hline
\end{tabular}

Abreviações: Am (\%)=Percentual de areia média em \%; Mz (Phi)=Tamanho do grão médio em phi; PDV=Potencial de deriva de vento em unidades de vetores (UV); VVAD= Variação do Volume acima do Datum em $\mathrm{m}^{3} / \mathrm{m}$. 
Tabela 16. Média e percentual de contribuição das variáveis para a formação do grupo 4 .

\begin{tabular}{lcc}
\hline Variáveis & Média & Contribuição (\%) \\
\hline Largura praia subaérea (m) & 69,25 & 20,92 \\
PDV & 39,17 & 18,41 \\
Azimute linha costa (graus) & 21,66 & 15,21 \\
VVAD (m $\left.{ }^{3} / \mathrm{m}\right)$ & 13,79 & 13,14 \\
Am $(\%)$ & 8,00 & 10,95 \\
Altura dunas frontais (m) & 4,18 & 7,67 \\
Declividade (\%) & 3,91 & 7,46 \\
Mz (phi) & 2.49 & 1.60 \\
\hline
\end{tabular}

Abreviações: Am (\%)=Percentual de areia média em \%; Mz (Phi)=Tamanho do grão médio em phi; PDV=Potencial de deriva de vento em unidades de vetores (UV); VVAD= Variação do Volume acima do Datum em $\mathrm{m}^{3} / \mathrm{m}$.

Tabela 17. Contribuição de cada variável para a dissimilaridade entre grupos em \%.

\begin{tabular}{lcccccc}
\hline Variáveis & $1 \times 4$ & $1 \times 2$ & $4 \times 2$ & $1 \times 3$ & $4 \times 3$ & $2 \times 3$ \\
\hline Largura praia subaérea $(\mathrm{m})$ & 34.01 & 26.64 & 27.01 & 16.93 & 28.89 & 27.43 \\
PDV & 0 & 36.97 & 27.10 & 25.47 & 34.24 & 0.00 \\
Azimute linha costa & 6.66 & 14.79 & 10.04 & 20.48 & 26.35 & 17.65 \\
VVAD & 6.12 & 6.10 & 3.34 & 5.06 & 5.45 & 4.12 \\
Am & 47.88 & 11.69 & 29.88 & 29.25 & 1.79 & 48.35 \\
Altura dunas frontais & 2.49 & 2.28 & 1.11 & 1.63 & 1.49 & 1.01 \\
Declividade & 2.23 & 1.44 & 1.12 & 1.10 & 1.41 & 1.28 \\
Mz & 0.62 & 0.09 & 0.40 & 0.08 & 0.38 & 0.16 \\
\hline
\end{tabular}

As variáveis que mais contribuíram para a dissimilaridade entre grupos, ou seja, as que os caracterizam e diferenciam, são: largura da praia subaérea, PDV, azimute da linha de costa e Am. As que menos os diferenciam são $\mathrm{Mz}$, declividade e altura das dunas frontais.

\section{Discussão dos resultados}

A largura da praia subaérea, o suprimento de sedimentos e a velocidade do vento atuam como os três principais fatores responsáveis pelo desenvolvimento da duna frontal (Davidson-Arnott \& Law, 1996). As praias dos grupos 1 e 4 possuem maior largura da praia subaérea, maior PDV, menores azimutes da linha de costa e maior VVAD dentre os grupos. A largura da praia subaérea é uma das características mais importantes para o transporte de sedimentos da praia para a duna (McLean \& Shen, 2006).

O maior PDV de um grupo com praia subaérea mais extensa (maior pista de vento) e menor azimute da linha de costa favorece uma incidência mais oblíqua do vento NE, o que facilita o transporte de sedimentos em direção ao continente e, consequentemente, aumento do volume do perfil e das dunas frontais no Grupo 1. Ventos oblíquos e com baixo a moderado ângulo de incidência são responsáveis por acresções na duna frontal e maior variabilidade topográfica no perfil (Hesp, 2002).

Estes dados, agora sob um enfoque mais quantitativo, corroboram as observações de Calliari et al. (2005), que indicavam que a orientação da linha de costa em relação ao vento NE influencia a efetividade regional do processo de transporte eólico e favorece o desenvolvimento de dunas mais altas no litoral norte próximo ao balneário de Dunas Altas ao sul de Cidreira.

0 grupo 3 apresentou a menor VVAD, resultado coerente com o maior azimute da linha de costa, ou seja, o vento dominante incide paralelamente e não transporta os sedimentos da praia subaérea para a duna frontal. O PDV desse grupo também é menor quando comparado aos grupos 1 e 4, o que reduz o potencial para o transporte eólico.

A largura da praia subaérea do grupo 2 é considerada igual a do grupo 3 , visto que a diferença entre ambas $(50 \mathrm{~cm})$ é menor que a precisão planimétrica do levantamento. Os valores próximos de largura da praia subaérea e VVAD são aparentemente incoerentes quando relacionados com a porcentagem de Am do grupo 2 (29,2\%) a qual é superior ao do grupo 3 (7,09\%), uma vez que propicia condições de praias intermediárias com maior distúrbio no fluxo do vento (Short \& Hesp, 1982). Entretanto, o menor azimute associado ao grupo 2 compensaria essa diferença granulomé- 
trica e favoreceria a entrada de areia de granulometria mais fina em direção as dunas frontais. Isso também ocorre em Dunas Altas (grupo 1), onde o fator relativo à obliquidade do vento, menor azimute da linha de costa, sobrepuja o efeito de diminuição da altura ocasionada pela presença de uma porcentagem maior de Am (35\%).

Os grupos que apresentam mais características em comum são o 1 e 4, apenas a Am e largura da praia subaérea foram relevantes para diferenciá-los. As variáveis que mais contribuíram para a dissimilaridade entre os grupos 1 e 2 foram PDV, largura da praia subaérea, azimute da linha de costa e Am. Entre os grupos 4 e 2 os resultados são semelhantes aos dos grupos 1 e 2, porém o percentual de Am é 21,20\% menor no grupo 4, indicando que a menor quantidade de areia média favorece perfis mais suaves, característicos de praias dissipativas e, consequentemente, maior altura das dunas frontais. Entre os grupos 1 e 3, o percentual de Am foi a variável que mais contribuiu para diferenciá-los. Ambos podem ser considerados grupos extremos, ou seja, os balneários pertencentes ao grupo 1 estão associados a praias que apresentam tendências dissipativas. Já os do grupo 3 com praias mais intermediárias, caracterizadas pelo menor desenvolvimento de dunas frontais.

0 grupo 3 apresenta o menor PDV e maior azimute, ou seja, menor potencial para o transporte de sedimento entre todos os grupos. Isto se reflete no menor VVAD e altura das dunas frontais. Entre os grupos 4 e 3, a maior pista de vento, PDV e largura da praia subaérea do primeiro associado ao menor azimute resultou em maior VVAD e altura das dunas frontais, nesse caso o Am pouco contribuiu para diferenciá-los. Entre os grupos 2 e 3 as variáveis que tiveram maior participação na diferenciação foi o Am, largura da praia e azimute da linha de costa.

Os resultados apresentados acima correspondem aos já descritos na bibliografia, onde dunas frontais maiores ocorrem em praias largas, dissipativas e com o máximo potencial para o transporte de areia e dunas menores em praias estreitas, com mínimo potencial para o transporte eólico, intermediárias a reflectivas (Hesp, 1988).

O campo de dunas, das praias do grupo 1 , é iniciado no balneário Dunas Altas, formado por grandes dunas frontais contínuas, com até $10 \mathrm{~m}$ de altura e $90 \mathrm{~m}$ de largura, por dunas parabólicas, constituídas por grandes lobos de deposição e bacias de deflação com até $160 \mathrm{~m}$, e blowouts. Essa formação modifica-se no campo de dunas ao norte de Palmares do Sul, onde as dunas frontais são fragmentadas e de menor magnitude, os lobos de deposição e bacias de deflação são menores, quando comparados a Dunas Altas, e pequenos blowouts ocorrem. O campo de dunas iniciado ao norte de Imara (Imbé, RS) é caracterizado por um cordão de dunas frontais delgado com pequenos blowouts, onde não há presença de lobos de deposição e bacias de deflação indicando o sentido de migração das dunas.

Martinho et al. (2010) ao analisar as seguintes praias do grupo 1, Magistério (Balneário Pinhal) e Dunas Altas, caracterizaram os campos de dunas das mesmas como de grande largura, com bacias de deflação e rastros lineares ocasionados pela ação do vento dominante, sendo em Dunas Altas, os campos de dunas com mais sedimentos disponíveis. Esses campos de dunas tiveram aumentos nas bacias de deflação em um período de 50 anos com redução na área ocupada por barcanóides e dunas transversais. Em Dunas Altas e Magistério, áreas sem vegetação ocupadas por barcanas e barcanóides foram transformadas nesse período em pequenas dunas parabólicas.

Baseado nos resultados encontrados na bibliografia, o grupo 1 possui potencial eólico para o transporte de sedimentos e formação de dunas frontais de grande a moderada altura em função da maior largura da praia subaérea, consequentemente maior quantidade de sedimento disponível para o transporte e maior pista de vento, e PDV. Praias com tendências dissipativas (grupo 1) também são menos vulneráveis a processos erosivos ocasionados pela ação de tempestades. 0 desenvolvimento morfológico das dunas frontais depende do suprimento de areia, padrão de transporte eólico, frequência e magnitude de tempestades de ondas, dentre outros (Hesp, 2002).

As praias pertencentes ao grupo 2 possuem nos trechos preservados pequenas bacias de deflação e lobos de deposição, com tamanho máximo de $100 \mathrm{~m}$, blowouts de pequena magnitude e um cordão de dunas frontais delgado, constantemente interrompido por sangradouros, sem a ocorrência de rastros lineares. Em alguns pontos, o cordão de dunas frontais é formado por pequenas dunas parabólicas. A geomorfologia em Arroio do Sal é constituída por pequenas dunas frontais com sequências de discretos blowouts e dunas parabólicas em alguns pontos.

Os campos de dunas de Arroio do Sal e Capão da Canoa apresentam uma geomorfologia tipo montícular arredondada, descontínua, com barcanóides e dunas transversais restritas pela presença de sangradouros (Hesp et al., 2007). Na década de 40, o campo de dunas de Capão Novo era dominado por dunas ativas com barcanóides e dunas 
transversais, sem bacias de deflação. Na década de 70 , o campo de dunas tinha desenvolvido algumas bacias de deflação, especialmente ao redor de sangradouros e, na década seguinte, apresentava-se mais vegetado e deflacionado com dunas mais planas, modificação essa ocasionada pela urbanização (Martinho et al., 2010). Parte do campo de dunas ocupado por barcanóides e dunas transversais foi transformada em campo de dunas parabólicas com algumas solitárias barcanóides (Martinho et al., 2010). Com isso, as praias constituintes do grupo 2 apresentam potencial para o transporte eólico com dunas frontais de largura moderada.

Praias pertencentes ao grupo 3, situadas no município de Torres, com exceção da Praia da Cal, possuem geomorfologia muito particular, quando comparada às demais, pela presença de diversos afloramentos rochosos que se estendem a zona de arrebentação. As praias ao sul desse grupo apresentam um cordão de dunas frontais segmentado, delgado, seguindo a orientação do vento dominante em alguns pontos. Pequenos lobos de deposição podem ser encontrados na praia Estrela do Mar assim como alguns blowouts do tipo trough. Pequenas massas de areia formam o cordão de dunas frontais no balneário Yara. Na praia Riviera, o cordão de dunas frontais é plano e delgado em alguns pontos. Essa geomorfologia se repete até a praia de Itapeva, onde pequenos lobos de deposição são encontrados próximos de um afloramento rochoso, que se estende por, aproximadamente, $198 \mathrm{~m}$ de praia.

O campo de dunas do Parque Estadual de Itapeva é limitado a oeste pelo afloramento rochoso, apresentando alguns lobos de deposição, pequenos blowouts e dunas frontais descontínuas. No Parque Guarita, o cordão de dunas é praticamente inexistente, resumindo-se a pequenos depósitos de sedimento sobre as rochas. Essas características, associada aos demais parâmetros morfométricos e a estudos anteriores, enquadram essas praias como de moderado potencial para transporte eólico.

0 grupo 4, constituído por balneários pertencentes ao município de Tramandaí apresenta, nos trechos preservados diversos rastros lineares formados pela ação do vento dominante, com os braços ancorados pela vegetação, blowouts do tipo trough e saucer, lobos de deposição e um cordão de dunas frontais segmentado e afilado em alguns pontos. Sequências de blowouts do tipo saucer são frequentes no campo de dunas ao sul desse grupo, assim como bacias de deflação e sangradouros de ocorrência natural. Na década de 40 , as dunas barcanóides observadas em Jardim do Édem fo- ram transformadas para parabólicas na década de 70. Vinte e nove anos depois, as bacias de deflação desses balneários foram divididas em lotes para urbanização e pequenas barcanas começaram a aparecer na área ocupada anteriormente por barcanóides e dunas transversais (Martinho et al., 2010). As praias desse grupo podem ser classificadas como de moderado a alto potencial para o transporte eólico de sedimento e dunas frontais de largura moderada a alta.

\section{Conclusões}

O sistema Lidar provou ser uma valorosa ferramenta para estudos de sistemas costeiros, a precisão e detalhe fornecido pelos sensor, em tempo rápido, permite que se avalie fenômenos que ocorrem em curtos espaços de tempo. Através da geomorfologia obtida com o grau de detalhe do Lidar, foi possível identificar os processos eólicos atuantes na definição das principais feições. Assim, blowouts, campos de dunas e dunas parabólicas foram identificadas e os padrões geomorfológicos encontrados correspondem aos descritos na literatura para praias dissipativas e intermediárias.

Técnicas de estatística multivariada se mostraram adequadas para a organização dos diferentes balneários em grupos de afinidade. Quatro grupos foram obtidos com essas análises. 0 grupo 1 iniciado em Dunas Altas prolongando-se até Salinas, onde é interrompido pelo grupo 4 que abrange o campo de dunas de Tramandaí até Tramandaí Sul. 0 grupo 1 reinicia na Zona Nova extensão Sul (Tramandaí) seguindo até Mariápolis (Osório). 0 grupo 2 estende-se do limite sul de Xangri-lá até o limite norte de Arroio do Sal, também faz parte desse grupo a Praia da Cal. 0 grupo 3 é constituído pelos balneários do município de Torres, Paraíso até Praia Grande, com exceção da Praia da Cal.

As variáveis que mais contribuíram para a dissimilaridade entre grupos, ou seja, as que os caracterizam e diferenciam, são: largura da praia subaérea, PDV, azimute da linha de costa e Am. Isso indica diferenciação na altura das dunas frontais e geomorfologia do campo de dunas interior.

Fatores físicos regionais, tais como a orientação da linha de costa em relação ao vento predominante, são fundamentais no desenvolvimento e na morfologia das dunas, independente do estágio praial. A associação entre largura de praia, PDV e baixo azimute da linha de costa em relação ao vento predominante são fatores que explicam a diferenciação entre os grupos.

Através da morfometria obtida com o grau de detalhe do Lidar foi possível diagnosticar os 
fatores responsáveis pela diferenciação do sistema praia dunas no litoral norte do RS assim como identificar as feições geomorfológicas características de cada grupo.

\section{Referências}

Almeida, L.E.S.B., Rosauro, N.M.L. \& Toldo Jr., E.E. 1997. Análise Preliminar das Marés na Barra do Rio Tramandaí, RS. In: SIMPÓSIO BRASILEIRO DE RECURSOS HÍDRICOS, 12, Vitória. Anais..., Vitória, ABRH, v.1, p. 560-566.

Bagnold, R.A. 1941. The physics of blown and desert dunes. Londres, Chapman and Hall, 265p.

Barletta, R.C. 2001. Efeito da Interação Oceano-Atmosfera Sobre a Morfodinâmica das Praias do Litoral Central do Rio Grande do Sul, Brasil. Rio Grande, 134p. Dissertação de mestrado, Programa de Pós graduação Oceanografia, Física, Química e Geológica, Instituto de Oceanografia, Universidade Federal do Rio Grande.

Battiau-Queney, Y., Billet, J.F., Chaverot, S. \& Lanoy-Ratel, P. 2003. Recent shoreline mobility and geomorphic evolution of macrotidal sandy beaches in the north of France. Marine Geology, 194: 31-45.

Calliari, L.R. Pereira, P. S., De Oliveira, A.O. \& Figueiredo, S.A. 2005. Variabilidade das dunas frontais no litoral norte e médio do Rio Grande do Sul. Gravel, 3: 15-30.

Calliari, L., Toldo Jr., E.E. \& Nicolodi, J.L. 2006. Classificação Geomorfológica. In: Muehe, D. (Ed). Erosão e progradação do litoral brasileiro. Brasília, Ministério do Meio Ambiente, p. 438-444.

Clarke, K.R. \& Gorley, R.N. 2006. PRIMER v6: User Manual/Tutorial. Plymouth, Primer-E Ltd, 189p.

Davidson-Arnott, R.G.D. \& Law, M.N. 1996. Measurement and prediction of long-term sediment supply to Coastal Foredunes. Journal of Coastal Research, 12: 654-663.

Dillenburg, S.R. \& Hesp, P.A. 2009. Geology and Geomorphology of Holocene Coastal Barriers of Brazil. Heidelberg, Springer, 380p.

Dillenburg, S.R., Barboza, E.G., Tomazelli, L.J., Rosa, M.L.C.C. \& Maciel, G.S. 2013. Aeolian Deposition and Barrier Stratigraphy of the Transition Region between a Regressive and a Transgressive Barrier: an example from Southern Brazil. In: INTERNATIONAL COASTAL SYMPOSIUM, 12, Plymouth. Anais..., Plymouth, CERF-JCR, v.1, p. 466-469.

Figueiredo, S.A. \& Calliari, L.J. 2005. Sangradouros: Distribuição espacial, variação sazonal, padrões morfológicos e implicações no gerenciamento costeiro. Gravel, 3: 47-57.

Gonçalves, G.A. 2010. Cartograma de ondulação geoidal do litoral norte do RS. Rio Grande, Universidade Federal do Rio Grande.

Gray, J.S., Aschan, M., Carr, M.R., Clarke, K.R., Green, R.H., Pearson, T.H., Rosenberg, R., Warwick, R.M. 1988. Analysis of community attributes of the benthic macrofauna of Frierfjord/Langesundfjord and in a mesocosm experiment. Marine Ecology Progress Se- ries, 46: 151-165.

Hesp, P.A. 1988. Morphology, dynamics and internal stratification of some established foredunes in southeast Australia. Sedimentary Geology, 5: 17-41.

Hesp, P.A. 2002. Foredunes and blowouts: initiation, geomorphology and dynamics. Geomorphology, 48: 245-268.

Hesp, P.A., Dillenburg, S.R., Barboza, E.G., Clerot, L.C.P., Tomazelli, L.J. \& Ayup-Zouain, R.N. 2007. Morphology of the Itapeva to Tramandaí transgressive dunefield barrier system and mid- to late Holocene sea level change. Earth Surface Processes and Landforms, 32: 407-414.

Hoeke, R.K., Zarillo, G.A. \& Synder, M. 2001. A GIS Based Tool for Extracting Shoreline Positions from Aerial Imagery (BEACHTOOLS). Washington, US ARMY CORPS OF ENGINEERS, 12p.

Manly, B.F.J. 1994. Multivariate statistical methods: a primer. Londres, Chapman \& Hall, 215p.

Martinho, C.T., Hesp, P. A. \& Dillenburg, S.R. 2010. Morphological and temporal variations of transgressive dunefields of the northern and mid littoral Rio Grande do Sul coast, Southern Brazil. Geomorphology, 117: 14-32.

Martins, L.R. 1967. Aspectos deposicionais e texturais dos sedimentos praiais e eólicos da Planície Costeira do Rio Grande do Sul. Publicação Especial da Escola de Geologia, Universidade Federal do Rio Grande do Sul, 13: 1-102.

McLean, R. \& Shen, J.S. 2006. From foreshore to foredune: Foredune development over the last 30 years at Moruya Beach, New South Wales, Australia. Journal of Coastal Research, 22(1): 28-36.

Overton, M.F., Grenier, R.R., Judge, E.K. \& Fischer, J.S.1999. Identification and analysis of coastal erosion hazard areas: Dare and Brunswick Counties, North Carolina. Journal of Coastal Research, 28 (Special Issue): 69-84.

Pereira, P.S., Calliari, L.J., Barletta, R.C. 2010. Heterogeneity and homogeneity of Southern Brazilian beaches: A morphodynamic and statistical approach. Continental Shelf Research, 30: 270-280.

Robertson, W.V., Whitman, D., Zhang, K. \& Leatherman, S.P. 2004. Mapping shoreline position using airborne laser altimetry. Journal of Coastal Research, 20(3): 884-892.

Rossato, M.S. 2011. Os climas do Rio Grande do Sul: Variabilidade, tendências e tipologias. Porto Alegre. 240p. Tese de Doutorado, Programa de Pós-graduação em Geografia, Instituto de Geociências, Universidade Federal do Rio Grande do Sul.

Short, A., D. \& Hesp, P. A. 1982. Wave, beach and dune interactions in southeastern Australia. Marine Geology, 48: 259-284.

Strauch, J.C., Cuchiara, D.C., Toldo Jr., E.E. \& Almeida, L.E.S.B. 2009. 0 padrão de ondas de verão e outono no litoral sul e norte do Rio Grande do Sul. Revista Brasileira de Recursos Hídricos, 14(4): 29-37.

Toldo Jr., E.E., Almeida, L.E.S.B., Nicolodi, J.L. \& Martins, L.R. 2006. Erosão e acresção da zona costeira. In: Muehe, D. (Ed). Erosão e progradação do litoral 
brasileiro. Brasília, Ministério do Meio Ambiente, p. 468-475.

Tomazelli. L.J. 1993. 0 regime dos ventos e a taxa de migração das dunas eólicas costeiras do Rio Grande do Sul, Brasil. Pesquisas, 20(1): 18-26.

Tomazelli. L.J. \& Villwock, J.A. 2000. O Cenozóico no Rio Grande do Sul: Geologia da planície costeira. In: Holtz, M. \& De Ros, L.F. (Ed.). Geologia do Rio Grande do Sul. Porto Alegre: CIGO/UFRGS, p. 575-599.

Tozzi, H.A.M. 1999. Influência das tempestades extratropicais sobre o estoque subaéreo das praias entre Rio Grande e Chuí, RS. Campanha do outono e inverno de 1996. Porto Alegre, 115p. Dissertação de mestrado, Programa de Pós-graduação em Geociências, Ins- tituto de Geociências, Universidade Federal do Rio Grande do Sul, Rio Grande.

Travessas, F.A., Dillenburg, S.R. \& Clerot, L.C.P. 2005. Estratigrafia e evolução da barreira holocênica do Rio Grande do Sul no trecho Tramandaí-Cidreira. Boletim Paranaense de Geociências, 57: 57-73.

Wentworth, K.C. 1922. A scale of grade and class terms for clastic sediments. The Journal of Geology, 30(5): 377-392.

Zhang, K. \& Zheng, C. 2007. Airborne LIDAR data processing and analysis tools ALDPAT 1.0. Miami Nacional center for airbourne laser mapping. Disponível em: <http://lidar.ihrc.fiu.edu/download/Doc/ALDPAT.pdf $>$. Acesso em 12 dez. 2011.

Man 544.

Editores: César L. Schultz e Paulo A. de Souza. 